\title{
How Does Environmental Regulations Effect Pattern of Carbon Emission and Energy Efficiency: A Provincial Level Analysis of Chinese Energy- Intensive Industries?
}

Thanh Quang Ngo ( $\square$ thivietnguyen825@gmail.com )

University of Economics Ho Chi Minh City

\section{Research Article}

Keywords: Total factor energy efficiency, High energy-intensive industries, Environmental regulation, Nonradial directional distance function.

Posted Date: April 21st, 2021

DOl: https://doi.org/10.21203/rs.3.rs-443406/v1

License: (c) (1) This work is licensed under a Creative Commons Attribution 4.0 International License. Read Full License

Version of Record: A version of this preprint was published at Environmental Science and Pollution Research on August 13th, 2021. See the published version at https://doi.org/10.1007/s11356-021-15843W. 


\title{
How Does Environmental Regulations Effect Pattern of Carbon Emission and Energy Efficiency: A Provincial Level Analysis of Chinese Energy- Intensive Industries?
}

\author{
1 \\ Thanh Quang Ngo* \\ School of Government, University of Economics Ho Chi Minh City \\ Ho Chi Minh City, Vietnam. \\ Email: thanhnq@ueh.edu.vn \\ ORCID: http://orcid.org/0000-0001-8357-1957
}

Corresponding author: Thanh Quang Ngo (thanhonq@ueh.edu.vn)

\begin{abstract}
Energy has a huge environmental and economic implications in the modern community. Despite the rapid economic growth of China in the past two decades, it can further improve through sustainable green energy with more energy-efficient industries, so as to maintain a good balance between economic and social development. The performances of energy and carbon dioxide emissions are the critical indicators. On this basis, this work measures the impact of environmental regulations on energy efficiency based on 2008-17 panel data from 30 provinces in China. The total factor energy efficiency index (TFEEI) is calculated by the non-radial distance function (NDDF). In order to study the nonlinear relationship between environmental regulations and TFEEI, the dynamic threshold panel model is used under different environmental regulations, which can solve effectively endogenous problems and regional heterogeneity. The results show that, for energy-intensive industries, the overall average TFEEI level is still very low, with average values of 0.55 and 0.58 , which are well below the ideal value (i.e., 1). Further, the dynamic panel data model findings showed a Ushaped significant relationship between China's TFEEI and environmental regulation. The findings reveal that environmental regulation effect on TFEI rises steadily as the values of Market-Based Environmental Regulations (MERs) and Command and control Environmental Regulations (CCERs) and surpass the corresponding thresholds. This research can help policymakers understand the effectiveness of various levels of environmental legislation to make more informed decisions.
\end{abstract}

Keywords: Total factor energy efficiency; High energy-intensive industries; Environmental regulation; Non-radial directional distance function.

\section{Introduction}

Since the emergence of last century's energy turmoil, the energy issue has received massive attention in Chinese industries. Energy consumption and its impact on the environment are an important part of current social problems. The performances of energy and carbon dioxide 
emissions are the critical indicators for economic modelling. That is why, both energy and carbon dioxide emissions are considered in the analysis framework (Wang et al., 2019). At present, improving energy and carbon efficiency is one of the vital public policy concerns. The historic "Paris Agreement" set a below $2^{\circ} \mathrm{C}$ global temperature limit and started working to keep the temperature $1.5^{\circ} \mathrm{C}$ to take it to pre-industrial levels $1.5^{\circ} \mathrm{C}$ ( $\mathrm{Li}$ et al., 2018). A quick reduction of greenhouse gas emissions is critical to the success of this agreement. Under this circumstance, China is determined to reach a peak in carbon emission by 2030 . The country set the plan to reduce carbon emission per unit of GDP by $40-45 \%$ by 2020 and by $60-65 \%$ by 2030 considering 2005 as the base period (Liu et al., 2019b).

More than one third of the global energy is consumed by industries across the world. The proportion of $\mathrm{C}_{2}$ emission is slightly higher in this regard. The development model of China relies heavily on the industry, so local infrastructure development, manufacturing of exportoriented consumer products and heavy industrial equipment are highly supported by energyintensive production mechanisms. Therefore, the proportion of energy consumption with respect to carbon emission is higher than the world average in China (Zhang et al., 2020). The statistical report of 2010 from " the National Economic and Social Development states that processing of the raw materials of petroleum and chemical products, melting and crashing of metal, non-metal and ferrous metal products, electricity generation and distribution are considered high energy consuming activities. According to this report, all these sectors are segregated into sub-sector of Energy-intensive industries (Liu et al., 2019a). In 2015, Chinese energy-intensive companies emitted $79.68 \%$ of total carbon dioxide produced across the country (Fig. 1). Due to the rise of energy intensity and subsequent carbon emission, China faced massive international criticism, and this led the government to initiate a low carbon emission policy in its $13^{\text {th }}$ five-year plan from 2016 to 2020 by setting a maximum carbon emission limit for all the energy-intensive companies of the country. It is determined in the 
plan that the ferrous metal processing industry should decrease its energy use by a minimum of $10 \%$ while the rate for the petrochemical and the nonferrous metal industries, in this regard, is $18 \%$ (Chen and Lin, 2020).

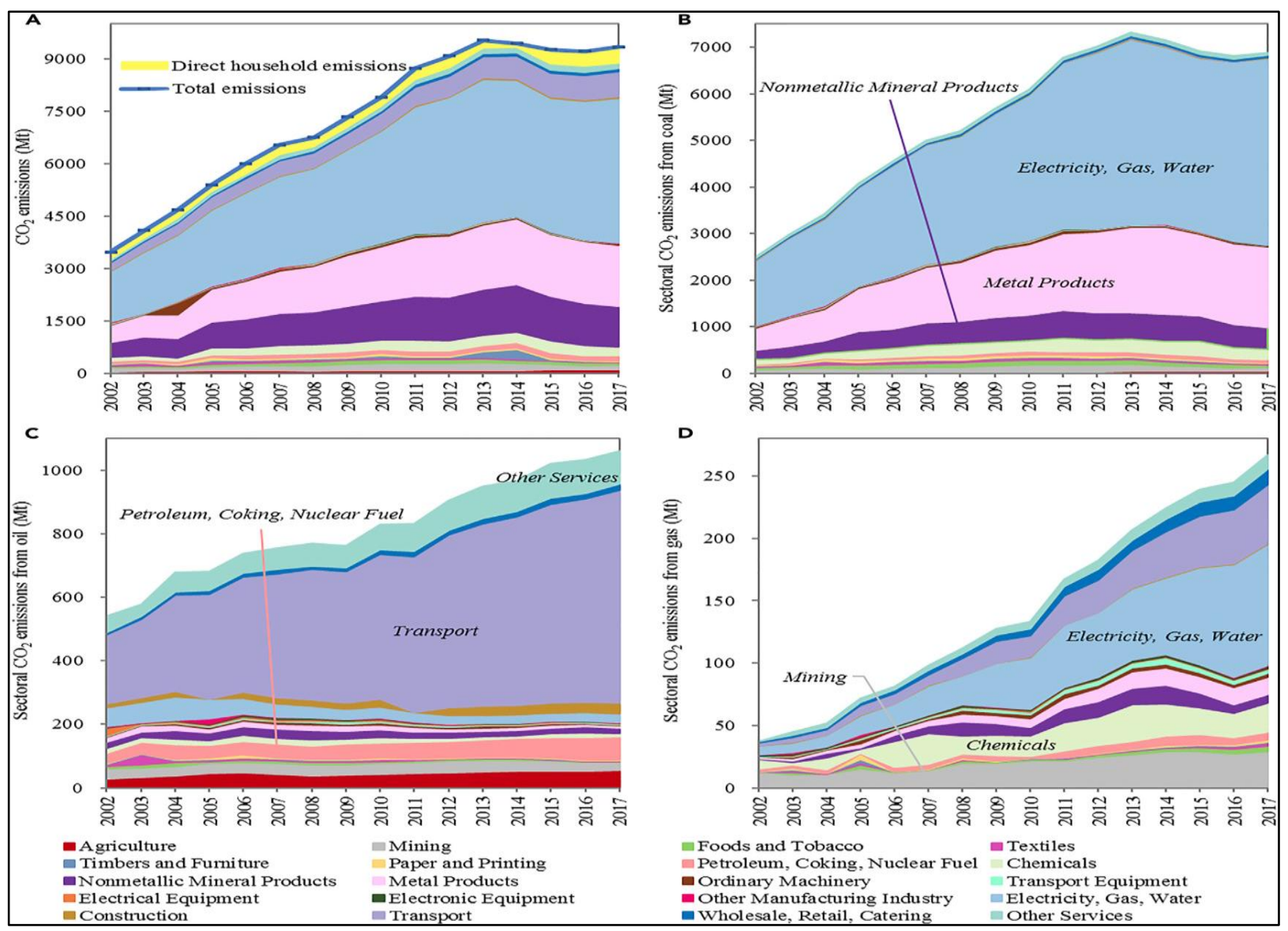

Fig. 1 Carbon emission scenario of Chinese industries (2002-2017)

Since fossil energy is considered to be the main factor in global warming, emphasizing the establishment of energy-efficient production and distribution processes may be the key to solving this hazardous issue (Meng et al., 2020). Economic developments across the nation are more or less correlated with energy intensity, carbon emission and global warming issues. Therefore, businesses and governments should care about the human and wildlife, climate, and environmental aspects while setting up their respective growth strategies. In this connection, initiation of the green movement by adopting green technology solutions for industrial production and distribution can be effective undertaking. A robust energy and carbon management and control, if possible, with a strict regulatory framework can also improve the 
environmental quality to a great extent. This study tries to examine the performance scale of the total factor energy efficiency indicator (TFEEI) from the year 2008 to 2017 for six highly energy-centric industries located in a different province of China. The non-radial directional distance function known as NDDF is applied to measure the performance of the aforementioned indices. Based on provincial panel data (2008 to 2017) of China's six major energy-intensive industries, this study investigates the current level of the Total Factor Energy Efficiency Index (TFEEI). The first step is to calculate the TFEEI of China's energy-intensive industries through the non-radial direction distance function (NDDF). Second, the impact of the environmental regulations (ER) and other vital factors on TFEEI is studied through the GMM method, by dividing the environmental regulations into market-based environmental regulations (MERs) and command and control environmental regulations (CCERs). The interaction term between environmental regulation and research and development (R\&D) is introduced to test the innovation offset effects by assessing the possible innovation offset. This work contributes to the literature in the following three ways: it uses the NDDF to evaluate and compare the TFEEIs of China's high energy-intensive industries at a provincial level (the NDDF minimizes environmental pollution as it maximizes economic benefits); the environmental regulations are divided into MERs and CCERs with the help of the systematic GMM estimation method (the effectiveness for various types of environmental regulations is validated through our research); the nonlinear and heterogeneous effects of environmental regulations on provincial TFEEI are assessed, and the TFEEI of China's high energy-intensive industry is measured. The industrial characteristics and regional heterogeneity of China's high energy-intensive industry are captured based on large-scale provincial panel data to calculate the effects of environmental regulations on TFEEI. This research can help form targeted environmental governance policies with guidance. 


\section{Literature review}

In this fast-paced globalized world, energy is the core of strong economic growth, but this energy is also the root cause of global climate change. In this case, decision makers need to formulate economic development strategies, taking into account environmental sustainability issues (Sadiq et al., 2020). There is a mature argument that paying attention to the development of energy-saving production technology may be a major measure to solve the current climate problem. Some studies are supporting this claim. For example, Wang et al. (2017) studied the energy-saving potential of 17 of the 17 Asia-Pacific Economic Cooperation (APEC) countries. Nassiri and Singh (2009) evaluated the energy performance of 21 Organization for Economic Cooperation and Development (OECD) countries by adopting both parametric and nonparametric approaches. Khoshnevisan et al. (2013) also studied the energy efficiency of 23 developing economies and concluded that the role of a strict energy policy is the key to ensure energy efficient production and environment. Moreover, the study of Chien et al. (2021); Geng et al. (2019) on 15 EU countries revealed that creating alternative energy sources and popularizing their use among industries and households can lessen pressure on fossil energy but improve the productivity comparatively. Meanwhile, (Song et al., (2013) and (Li and Lin, 2017) studied the provincial energy efficiency of China and concluded that technological advancement in the industry sector can lead to attaining energy efficient economic growth. Researchers have adopted a variety of energy efficiency measures to study the energy and environmental efficiency levels of many different countries and regions. Data Envelopment Analysis (DEA) is one of the most popular and effective tools for measuring energy and environmental performance. Despite having some limitations, the DEA application has some advantages in evaluating energy efficiency. This study reviews the DEA application used by previous studies on the issues of energy and environmental efficiency and the decomposition of the Malmquist index. For example, ( Shao et al., 2014) and (Chen and Lin, 2020) applied 
DEA to measure energy efficiency within the metal sector and Ma et al. (2019) studied both energy and pollution efficiency for the mining industry of China. Besides, Lin and Jia (2019) evaluated the efficiency of environmental governance for the energy industry of China energy industry. Moreover, Yang et al. (2020) measured the energy efficiency of the manufacturing industry by applying Malmquist index decomposition, Stochastic Frontier Method (SFA) and meta frontier DEA method and Lin and Chen (2019) measured the ecological efficiency of the non-ferrous metals industry of Chinese regions by applying non-radial DEA method. Du et al. (2020) conducted another study to explore the green total factor production efficiency and its determinants for the case of the metal industry in China with the application of sub-boundary and global DEA approaches. Apart from these studies, several other studies were conducted on the energy and environmental efficiencies for the steel, construction, and chemical industries of Chinese provinces. It is observed that current literature is based mainly on the energy efficiency of various industries of Chinese provinces. To the best of your knowledge, no prior studies objectively measured the energy and environmental performance of highly energyintensive industries of China from the operational front. In addition, it is observed that China is a huge territory and the different industrial sub-sectors that emerge along this territory affect the energy and environmental performance (EEP) of these regions. Therefore, by covering the heterogeneity of industries and regions, the total factor energy efficiency assessment of the six energy-intensive industries of Chinese provinces might help the policy makers to develop a sustainable strategy. It is further observed that the NDDF approach of efficiency measure is more flexible than any other measurement technique as it can satisfy the requirements of maximized economic growth and minimized pollution emissions. However, NDDF was used to assess the TFEEI of power sector only and no study is evident for such assessment regarding the six highest energy-intensive sectors. 
Therefore, this study uses the NDDF method for the TFEEI assessment of China's provincial energy-intensive industries to fill this research gap. Due to the extensive acceleration of ecological degradation, governments have undertaken a bunch of corrective measures to tackle and promote sustainable development. Research by Poudineh et al. (2020) believes that the application of taxation can internalize the cost of external pollution, and according to this proposition, many policies have been adopted, such as command and control based environmental regulations (CCER) and market based environmental regulation (MER), etc. Other studies have shown that the formulation of regulations forces companies to increase expenditures or conduct environmental management and governance, and such enforcement will increase their operating costs and reduce economic benefits (Greenstone and Hanna, 2014; Peng, 2020; Zhang et al., 2021). However, according to Porter's hypothesis, a well-structured environmental regulatory framework can accelerate technological innovation, thereby reducing compliance costs.

Environmental regulations have significant causal relationship with both energy and environmental performance. For example, Jefferson et al. (2013) state that in China, such regulations can bring improved performance of the industry sector. Bi et al. (2014) also proposes that the thermal power generation sector of China can be made energy efficient if a well-regulated environmental atmosphere is in place. Recently, Lin and Chen (2020) showed that for both long run and short run energy efficiency, the contribution of MER is noteworthy but CER performed better in the short run. Zhang and Song (2021) also explored the nexus between environmental regulations and environmental control in the metal sector of Chinese territory and concluded that there is a nonlinear causal relationship among CCER and environmental control. However, they also concluded that CCER had no causality with environmental control. In addition, there are few studies to measure the degree of relationship between other control factors of energy efficiency. For example, Antonietti and Fontini (2019) 
considered economic development level, Y. Zhang et al. (2020) considered technology enhancement, and Xin-gang and Shu-ran (2020) considered energy price as the affecting variable for energy efficiency measure. In particular, it is currently unclear from the existing studies how different types of environmental regulations affect the TFEEI of the Chinese high energy intensive industries. The high energy intensive industries are the most polluting industries in China. Therefore, investigating the effect of environmental regulations on these industries is a timely attempt for ensuring an environmentally sustainable developed economy in China.

\section{Methodology and Variable Selection}

\subsection{The Non-radial directional distance function (NDDF) Model}

In the case of measuring the relative efficiency of any organization (Decision Making Unit), The application of DEA is widely accepted. The DEA method is mainly an input-output based measure of production efficiency. DEA is applied to measure the economic efficiency of many different sectors and nowadays this method has received popularity for measuring environmental efficiency. After (Zhou et al., 2007) applied the NDDF method to measure the energy and environmental performance of the Chinese provinces. In the NDDF approach, capital (K), labor (L), and energy (E) are considered as input and industry output (Y) is considered as output. Meanwhile, $\mathrm{CO} 2$ is regarded as undesirable or bad output. For applying DEA in any efficiency measure, the formation of a production possibility set (PPS) is mandatory. Therefore, this study constructs a PPS which is stated equation. (1) (Zhou et al., 2006).

$$
P=\{(L, K, E, G D P, C O 2):(L, K, E) \text { can produce }(G D P, C O 2)\}
$$


In the above equation, P stands for the PPS L, K, E stand for labour, capital, and energy. The PPE states that it is possible to produce out $\mathrm{Y}$ and $\mathrm{C}$ from the input $\mathrm{K}, \mathrm{L}$, and $\mathrm{E}$. Table 1 shows the descriptive statistics for the input and output variables of this study.

Table 1. Descriptive statistics of variables

\begin{tabular}{|c|c|c|c|c|c|c|c|c|c|c|c|}
\hline & & \multicolumn{5}{|c|}{ Electricity sector } & \multicolumn{5}{|c|}{ Ferrous metals sector } \\
\hline & & $\begin{array}{l}\text { Bad } \\
\text { output }\end{array}$ & $\begin{array}{l}\text { Good } \\
\text { output }\end{array}$ & Input 1 & Input 2 & $\begin{array}{l}\text { Input } \\
3 \\
\end{array}$ & $\begin{array}{l}\text { Bad } \\
\text { output }\end{array}$ & $\begin{array}{l}\text { Good } \\
\text { output }\end{array}$ & $\begin{array}{l}\text { Input } \\
1\end{array}$ & Input 2 & $\begin{array}{l}\text { Input } \\
3\end{array}$ \\
\hline \multirow[t]{4}{*}{2008} & Max & 126.2 & 71.9 & 19.2 & 1435.1 & 24.4 & 51.3 & 69.8 & 33.5 & 781.3 & 23.4 \\
\hline & Min & 3.7 & 1.6 & 1.3 & 0.7 & 0.3 & 0.1 & 0.4 & 0.1 & 0.7 & 0.01 \\
\hline & Mean & 51.6 & 17.0 & 7.63 & 420.5 & 8.8 & 10.7 & 19.1 & 8.3 & 145.1 & 6.9 \\
\hline & $\mathrm{SD}$ & 34.5 & 14.8 & 4.4 & 282.5 & 6.7 & 11.9 & 18.9 & 7.4 & 176.2 & 6.2 \\
\hline \multirow[t]{4}{*}{2012} & Max & 267.8 & 243.9 & 20.5 & 2371.5 & 37.3 & 148.9 & 275.7 & 39.9 & 1011.4 & 69.3 \\
\hline & Min & 7.5 & 6.2 & 1.6 & 43.2 & 0.8 & 0.1 & 0.8 & 0.2 & 2.0 & 0.04 \\
\hline & Mean & 90.7 & 53.6 & 8.4 & 825.0 & 14.3 & 23.6 & 62.2 & 9.6 & 245.8 & 14.4 \\
\hline & $\mathrm{SD}$ & 66.8 & 51.5 & 4.9 & 537.5 & 10.5 & 28.6 & 70.2 & 9.1 & 263.7 & 16.1 \\
\hline \multirow[t]{4}{*}{2015} & Max & 373.9 & 436.4 & 22.0 & 5825.9 & 58.0 & 259.2 & 589.0 & 54.7 & 2299.6 & 106.0 \\
\hline & Min & 9.8 & 11.2 & 1.2 & 252.3 & 0.2 & 0.6 & 0.5 & 0.1 & 4.2 & 0.04 \\
\hline & Mean & 131.2 & 107.0 & 9.2 & 2441.1 & 18.8 & 42.0 & 130.3 & 11.5 & 510.1 & 25.4 \\
\hline & $\mathrm{SD}$ & 93.3 & 95.2 & 5.4 & 1325.0 & 13.5 & 49.9 & 146.7 & 11.7 & 523.4 & 27.2 \\
\hline \multirow[t]{6}{*}{2017} & Max & 453.9 & 761.2 & 20.4 & 12831.4 & 60.7 & 324.7 & 803.7 & 62.7 & 5484.3 & 126.5 \\
\hline & Min & 14.0 & 24.9 & 1.2 & 850.4 & 1.1 & 0.1 & 1.2 & 0.1 & 8.7 & 0.06 \\
\hline & Mean & 148.2 & 182.8 & 9.4 & 5559.4 & 18.2 & 47.5 & 168.5 & 12.5 & 1237.3 & 27.5 \\
\hline & $\mathrm{SD}$ & 112.9 & 166.7 & 5.1 & 2911.8 & 14.1 & 63.2 & 200.4 & 13.3 & 1246.8 & 30.7 \\
\hline & & \multicolumn{5}{|c|}{ Non-metallic products sector } & \multicolumn{5}{|c|}{ Petroleum sector } \\
\hline & & $\begin{array}{l}\text { Bad } \\
\text { output }\end{array}$ & $\begin{array}{l}\text { Good } \\
\text { output }\end{array}$ & $\begin{array}{l}\text { Input } \\
1 \\
\end{array}$ & Input 2 & $\begin{array}{l}\text { Input } \\
3 \\
\end{array}$ & $\begin{array}{l}\text { Bad } \\
\text { output }\end{array}$ & $\begin{array}{l}\text { Good } \\
\text { output }\end{array}$ & $\begin{array}{l}\text { Input } \\
1\end{array}$ & Input 2 & $\begin{array}{l}\text { Input } \\
3 \\
\end{array}$ \\
\hline \multirow[t]{4}{*}{2008} & 2008 & 27.5 & 51.5 & 38.6 & 371.1 & 6.4 & 16.5 & 72.1 & 8.4 & 321.7 & 31.4 \\
\hline & Min & 1.2 & 0.8 & 0.7 & 0.7 & 0.1 & 0.1 & 0.01 & 0.01 & 0.3 & 0.01 \\
\hline & Mean & 10.2 & 13.0 & 13.1 & 94.8 & 2.4 & 2.9 & 15.4 & 2.0 & 73.5 & 6.6 \\
\hline & $\mathrm{SD}$ & 7.6 & 14.0 & 10.6 & 80.0 & 1.8 & 3.7 & 16.8 & 2.2 & 83.7 & 8.3 \\
\hline \multirow[t]{4}{*}{2012} & 2012 & 54.7 & 153.0 & 53.8 & 595.5 & 13.9 & 34.3 & 150.3 & 17.3 & 405.0 & 40.0 \\
\hline & Min & 1.8 & 1.2 & 0.8 & 6.4 & 0.3 & 0.1 & 0.02 & 0.01 & 0.3 & 0.1 \\
\hline & Mean & 16.2 & 27.2 & 13.9 & 158.8 & 3.9 & 5.5 & 34.9 & 2.5 & 109.2 & 11.0 \\
\hline & $\mathrm{SD}$ & 12.9 & 34.2 & 13.0 & 129.3 & 3.0 & 6.5 & 36.5 & 3.2 & 105.0 & 11.7 \\
\hline \multirow[t]{4}{*}{2015} & 2015 & 60.9 & 355.5 & 62.1 & 3103.6 & 19.3 & 39.3 & 311.3 & 17.1 & 1289.6 & 68.9 \\
\hline & Min & 3.6 & 4.6 & 1.0 & 29.0 & 0.4 & 0.3 & 1.5 & 0.1 & 21.5 & 0.1 \\
\hline & Mean & 26.1 & 81.4 & 18.1 & 715.6 & 5.8 & 8.2 & 73.6 & 3.1 & 360.0 & 16.6 \\
\hline & $\mathrm{SD}$ & 18.1 & 88.6 & 16.7 & 675.9 & 4.8 & 9.3 & 75.4 & 3.5 & 306.9 & 16.9 \\
\hline 2017 & 2017 & 74.3 & 637.0 & 83.2 & 9213.9 & 71.6 & 47.4 & 569.9 & 11.9 & 2998.5 & 91.9 \\
\hline
\end{tabular}




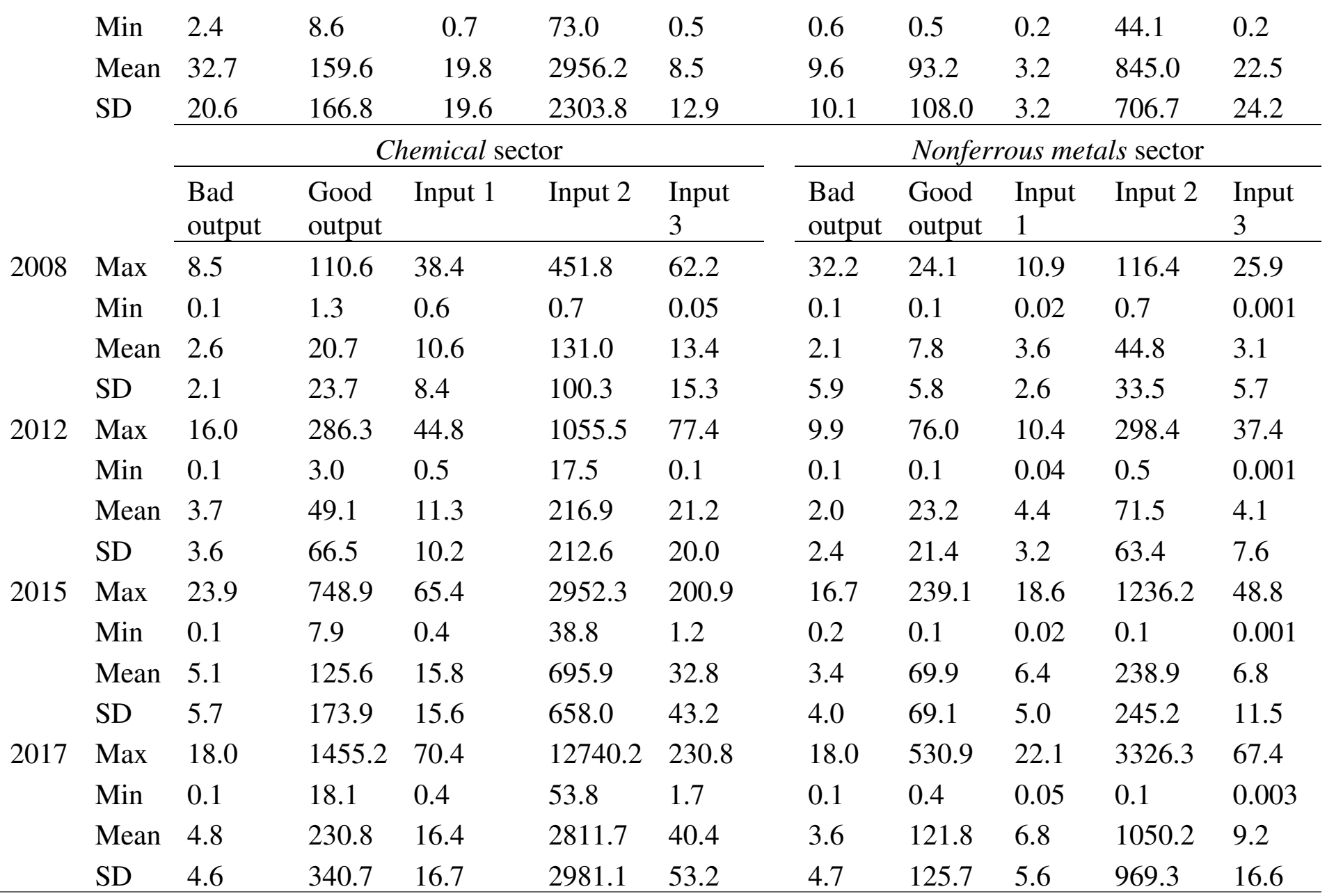

Chung et al. (1997) suggested the Directional Distance Function (DDF) and it was used by the previous researchers for efficiency measurement. This method considers only desirable output in calculating production efficiency. But, with the emergence of the $\mathrm{CO}_{2}$ emission rise issue, the dimension of efficiency calculation was altered by subsequent researchers. Following this (Zhang and Choi, 2014) considered $\mathrm{CO}_{2}$ emission as a bad output and incorporated it in the DDF model. Färe and Grosskopf (2010) also applied the DDF method for measuring efficiency by considering $\mathrm{CO}_{2}$ as a bad output. However, the DDF method considers an equal proportion of changes in the input-output matrix which might give an overestimated efficiency outcome (Lin and Du, 2015). To remove this shortcoming, (Zhou et al., 2012) applied the non-radial direction distance function (NDDF) which considers real production characteristics and accepts the non-proportional changes in both desirable and undesirable output variables. Later, 
Zhang and Choi (2013) applied NDDF for exploring the efficiency of Chinese power plants and found the method a more robust one for efficiency analysis.

1: If $(L, K, E, G D P, C O 2 \in P$ and $0 \leq \theta \leq 1$ then $(L, K, E, \theta G D P, \theta C O 2)$

2: If $L, K, E, G D P, C O 2 \in P$ and $G D P=0, C O 2=0$ )

Zhang et al. (2014) state that the hypothesis of weak disposability means reducing the undesired output $\mathrm{C}$ will reduce the cost of the expected output $\mathrm{O}$, while the zero joint hypothesis indicates that the undesired output $\mathrm{C}$ will inevitably be produced during the production process Such $\mathrm{T}$ is regarded as the environmental production technology (Zhou et al., 2012) and following this, $\mathrm{T}$ is estimated by applying the non-parametric DEA method. It is assumed that there are $\mathrm{n}$ DMUs and $\mathrm{T}$ is represented by the constant return to scale in equation (2):

$P=\left\{(L, K, E, G D P, C O 2): \sum_{n=1}^{N} Z_{n} K_{n} \leq K, \sum_{n=1}^{N} Z_{n} L_{n} \leq L, \sum_{n=1}^{N} Z_{n} E_{n} \leq\right.$ $E, \sum_{n=1}^{N} Z_{n} G D P_{n} \geq G D P, \sum_{n=1}^{N} Z_{n} C O 2_{n}=C O 2$

$Z_{n}$ stands for the intensity variable to form constructing T as a convex expression (Chung et al., 1997). The NDDF is further used to calculate the EEP of each DMU which is represented as Eq. (3):

$$
\vec{D}(L, K, E, G D P, C O 2)=\sup \left\{W^{T} B:(L, K, E, G D P, C O 2)+G \times \operatorname{diagonal}(\beta)\right) \in T
$$

Where $W^{T}$ is regarded as a normalized weight vector; and $G$ represented as the directional vector and $\beta$ is represented as the vector for scaling factor.

\subsection{Formation of the Energy Efficiency Index}

The total-factor NDDF (TNDDF) is constructed to evaluate the TFEEI by taking in to account the existence substitution effect between the energy and other variables. The construction of the model is portrayed below: 


$$
\overrightarrow{D_{T}}(L, K, E, G D P, C O 2 ; G)=\max \cdot w_{k} \beta_{k}+w_{L} \beta_{L}+w_{E} \beta_{E}+w_{G D P} \beta_{G D P}+w_{C O 2} \beta_{C O 2}
$$

s.t.

$$
\begin{gathered}
\sum_{n=1}^{N} Z_{n} K_{n} \leq K-\beta_{K} g_{K}, \sum_{n=1}^{N} Z_{n} L_{n} \leq L-\beta_{L} g_{L}, \sum_{n=1}^{N} Z_{n} E_{n} \leq E-\beta_{E} g_{E}, \\
\sum_{n=1}^{N} Z_{n} G D P_{n} \geq G D P+\beta_{G D P} g_{G D P}, \sum_{n=1}^{N} Z_{n} C O 2_{n}=C O 2-\beta_{c o 2} g_{c o 2} \\
Z_{n} \geq 0, n=1,2,3, \ldots \ldots, N, \beta_{K}, \beta_{L}, \beta_{E}, \beta_{G D P}, \beta_{C O 2} \geq 0
\end{gathered}
$$

If $\vec{D}(L, K, E, G D P, C O 2)=0$, it denotes that the DMU moves towards the efficient frontier in G direction. Here the weight vector is $W^{T}=\left(\frac{1}{9}, \frac{1}{9}, \frac{1}{9}, \frac{1}{3}, \frac{1}{3}\right)$. By following the studies of Zhou et al. (2012) and Barros et al. (2012), this study treats the inputs and both the desirable and the undesirable outputs with the same weight. Therefore, each of the variables is assigned with a weight of $1 / 3$. Moreover, the weight of the input variables is evenly distributed to $K, L$ and $E$; that is, the weight for each input factor is $1 / 9$. furthermore, the directional vector is set as $G=$ $(-K,-L,-E,-G D P,-C O 2)$. The optimal solution might be attained through solving equation 4 to get the TFEEI.

$$
\begin{gathered}
T F E E I_{n}=\frac{1}{4}\left[\frac{G D P_{n} / K_{n}}{\left(G D P_{n}+\beta_{n 0}^{*} G D P_{n}\right) /\left(K_{n}+\beta_{n k}^{*} K_{n}\right)}+\frac{G D P_{n} / L_{n}}{\left(G D P_{n}+\beta_{n 0}^{*} G D P_{n}\right) /\left(L_{n}+\beta_{n L}^{*} L_{n}\right)}+\right. \\
\left.\frac{G D P_{n} / E_{n}}{\left(G D P_{n}+\beta_{n 0}^{*} G D P_{n}\right) /\left(E_{n}+\beta_{n E}^{*} E_{n}\right)}+\frac{G D P_{n} / C O 2_{n}}{\left(G D P_{n}+\beta_{n 0}^{*} G D P_{n}\right) /\left(C O 2_{n}+\beta_{n c o 2}^{*} C O 2_{n}\right)}\right](5) \\
T F E E I_{n}=\frac{1-\frac{1}{4}\left(\beta_{n k}^{*}+\beta_{n L}^{*}+\beta_{n E}^{*}+\beta_{n c o 2}^{*}\right)}{1+\beta_{n 0}^{*}} \mathrm{n}=1,2,3,,, \mathrm{~N}
\end{gathered}
$$

\subsection{Econometric modelling and variable selection:}

\subsubsection{The Dynamic Panel Data Model Effect}

The following equation is constructed to find the relationship between environmental regulation and total factor energy efficiency:

$$
\operatorname{TFEEI}_{i t}=\alpha+\beta \mathrm{TFEEI}_{i, t-1}+\gamma \mathrm{ER}_{i t}+\theta X_{i t}+u_{t}+v_{i}+\varepsilon_{i t}
$$


In this equation, $\alpha$ represents the intercept and $\beta, \gamma$ and $\theta$ are coefficients to be estimated. $\mathrm{ER}_{i t}$ is the independent variable, that is, the vector that represents the command-and-control and market-based environmental regulation stringency? $\mathrm{EEI}_{i, t-1}$ is the first lag term of $\mathrm{EEI}_{i t}$. This lagged dependent variable $\mathrm{EEI}_{i, t-1}$ is added as the independent variable in constructing the equation considering the impact of lagged energy efficiency index on the current energy efficiency index and lagged environmental performance index on the current environmental performance index. $X_{i t}$ matrix indicates the control variables set. $u_{t}$ is fixed time effect, $v_{i}$ is a single fixed-effect, and $\varepsilon_{i t}$ is a random error term.

\subsubsection{The Dynamic Threshold Model}

The above-mentioned study carries some limitations as the model of moderating effects fails to identify the key areas and relevant breaks of environmental regulation. This study considers a single threshold model in line with the idea of (Hansen, 1999) non-dynamic panel threshold model, to explore the non-linear causality between environmental regulation and TFEEI, to confirm the rationality of sample interval segment and to reduce the errors in model estimate. The following section of this study addresses the environmental regulation variable as the threshold dependent variable to form a threshold effect model as below:

$$
T F E E I_{i t}=\alpha+\beta_{1} E E I_{i t-1}+\beta_{2} E R_{i, t} \circ I\left(Q_{i} \leq \mathrm{C}\right)+\delta_{1} E R_{i, t} \circ I\left(Q_{i}>\mathrm{C}\right)+\sum_{k=1}^{5} \delta_{k} X_{k i t}+
$$

In this model above, $\mathrm{C}$ is the estimated threshold value, and $I(\cdot)$ is the symptomatic function, which will be true if the corresponding condition is equal to 1 and false if the value is 0 . The results of the test might come up with the presence of multiple thresholds which can further be stretched to double and multiple threshold models from the base single threshold model.

\subsection{Variable and data source}

\subsubsection{Dependent variable}


The explanatory variable in this paper is total factor energy efficiency index (TFEEI).

\subsubsection{Independent variable}

This study takes i). Command and Control Environmental Regulation (CCER) and ii). Market based Environmental Regulation (MER) as the independent variables. The rationale behind choosing Command and Control Environmental Regulation (CCER) as one of the independent variables is that the significant part of the funding for environmental protection in China comes from public finance and the rest of the part comes from corporate and social financing. Therefore, the opportunity to invest in environmental development projects is huge and investment in this sector can be made in concurrent avenues such as in infrastructure, fixing problems with industrial pollution generation sites and environmental safety. Funding in identifying the source of industrial pollution (water or air disposal points for example) involves investing in environmental protection for a particular year. It can also involve investing in the previous years' pollution treatment projects. Present studies revealed that there is a positive link among the CCER and technological advancements and total factor production performance from the environmental front. The cost of pollution control in the form of spending in pollution treatments was considered as a proxy for CCER measurement by the previous researchers. Therefore, this study follows the earlier studies in framing the CCER index. Meanwhile, the Market incentive environmental regulation (MIER) is considered with the thought that sewerage charges are in many cases substituted for the pollution tax and this an choice is adopted by the government to make the environmental cost internal and stop pollution by the industries. In this regard, the Market incentive environmental regulation offers economic incentives to attain the quality of environment by charging the cost in disguise. Some studies have also considered levying fees on pollution to encourage companies to be innovative, thereby helping the government to strengthen environmental governance.

\subsubsection{Control variables}


This study considers foreign direct investment (FDI), urbanization flow, R\&D spending, export, industry structure and GDP as the control variables. All these variables are taken in support of the previous studies which show that these variables have an either unidirectional or bidirectional relationship with energy and environmental efficiency. This study uses the panel data for thirty Chinese provinces from 2003 to 2017. All the Data were collected from the National Bureau of Statistics of China. In table 2 the descriptive statistics of all the variables are presented. can be checked from table 2 .

Table 2. Summary statistics of the variables.

\begin{tabular}{cccccc}
\hline Variable & observation & Mean & S.D. & Max & Min \\
\hline TFEEI & 300 & 0.54 & 0.29 & 1.00 & 0.08 \\
CCER & 300 & 211732.77 & 199462.27 & 1416464.00 & 3527.00 \\
MER & 300 & 42356.49 & 43465.21 & 295540.00 & 90.00 \\
FDI & 300 & 0.03 & 0.03 & 0.15 & 0.00 \\
GDP & 300 & 19764.10 & 16140.87 & 85294.82 & 1070.46 \\
STR & 300 & 0.43 & 0.09 & 0.81 & 0.29 \\
RD & 300 & 1.52 & 1.08 & 6.12 & 0.34 \\
ECS & 300 & 19926.86 & 13136.38 & 67085.12 & 1801.55 \\
URBAN & 300 & 0.55 & 0.13 & 0.90 & 0.30 \\
\hline
\end{tabular}

\section{Empirical results and discussions}

Table 3 shows the results of the Total Factor Energy Efficiency Index (TFEEI) from 2008 to 2017 based on the non-radial directional distance function (NDDF). It can be seen that during the 2008-2017 study period, the average TEFEI of China's high energy-intensive (HEI) industries showed an upward trend. The overall level of average TFEEI is still very low, with an average value of 0.55 and 0.58 , which is far below the optimal value of 1 . China's energyintensive industries consume large amounts of energy and emit large amounts of carbon dioxide, resulting in low energy efficiency. This shows that China's high energy-intensive industries are responsible for high levels of carbon dioxide emissions, which ultimately makes these industries energy inefficient. However, the government of China has emphasized on pollution control measures and high emitting industries like petrochemical and metal will be 
under severe environmental scrutiny. For this environmental regulatory initiative, TFEEI for high carbon emission industries has greatly increased. This finding also goes in line with $(\mathrm{Wu}$ et al., 2020) who investigated the efficiency of energy and environment of Chinese mine sector. Table 3. The average TFEEI of China's high energy intensive industries from 2008 to 2017.

\begin{tabular}{rrrrrrrrrrr} 
& 2008 & 2009 & 2010 & 2011 & 2012 & 2013 & 2014 & 2015 & 2016 & 2017 \\
\hline TFEEI & 0.55 & 0.5 & 0.53 & 0.5 & 0.55 & 0.56 & 0.57 & 0.56 & 0.56 & 0.58
\end{tabular}

An increasing trend for the TFEEI scores of chemical, non-metal, ferrous, and non-ferrous metal industries is evident in Fig. 2, whereas, apart from 2012-2014, petroleum and electricity show a decreasing trend during the sample period. An improvement in the TFEEI of each industry from 2008 to 2017 suggests the consistency of the overall trend. With a mixed trend indicated by the chemical and ferrous metal sector, the non-metallic and ferrous metal sectors reflect the best results over the period under study. Most sectors of China experience a restructuring of resources, causing a temporary decline in TFEEI, with the Chinese economy entering the 'new normal' during the 12th FYP.

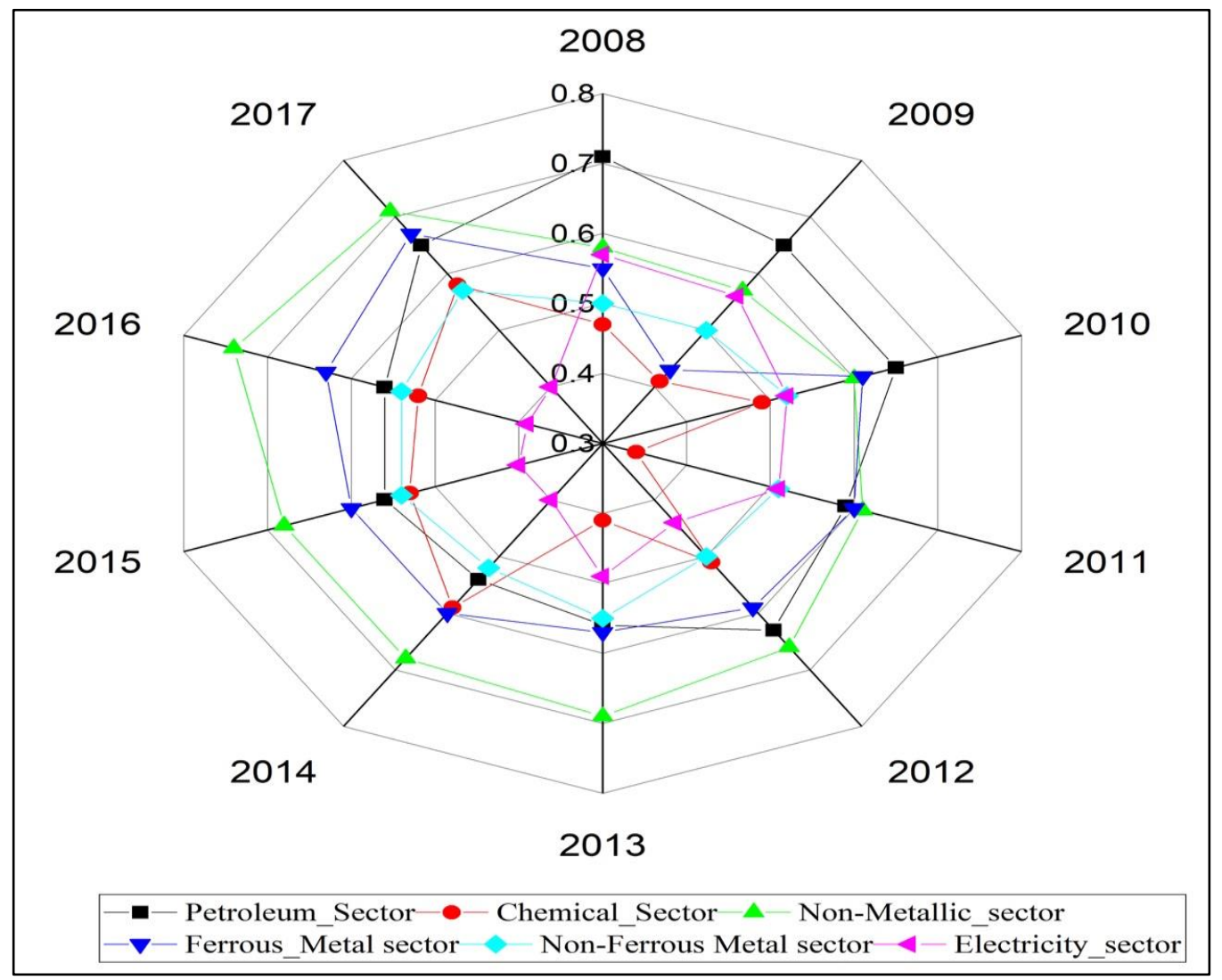


Figure 2. The TFEEI of China's six high energy-intensive industries from 2008 to 2017 According to Tab. 4, the highest TFEEI of energy-intensive industries on a provincial level is recorded in Hainan, Guangdong, Shanghai, Tianjin, Jiangsu, Zhejiang, Anhui, Jiangxi, Hubei, and Sichuan. The lowest TFEEI is recorded in Shanxi, Qinghai, Heilongjiang, Yunnan, Gansu, Xinjiang, and Ningxia. Provinces located in central and eastern regions have high TFEEI, and the provinces in western and north-east have low TFEEI. Compared to the central and eastern provinces, China's western provinces have a lower TFEEI due to a poor economic foundation and backward technological level. The high energy-intensive industries located in northeastern China's old industrial base developed earlier with a low TFEEI due to the outdated equipment and severe environmental pollution. Due to the extensive metal mining process and smelting using coal as the primary power source, a low TFEEI of high energy-intensive industries in Shanxi is easily noted.

Table 4. The TFEEI of China's six high energy-intensive industries at the provincial level from 2008 to 2017

\begin{tabular}{lccccccccccc}
\hline Province & 2008 & 2009 & 2010 & 2011 & 2012 & 2013 & 2014 & 2015 & 2016 & 2017 & Mean \\
\hline Anhui & 0.51 & 0.45 & 0.49 & 0.41 & 0.55 & 0.59 & 0.55 & 0.68 & 0.49 & 0.63 & 0.54 \\
Beijing & 0.88 & 0.87 & 0.94 & 0.88 & 0.97 & 0.93 & 0.88 & 1 & 1 & 1 & 0.94 \\
Chongqing & 0.47 & 0.45 & 0.41 & 0.51 & 0.37 & 0.44 & 0.26 & 0.34 & 0.33 & 0.38 & 0.4 \\
Fujian & 0.88 & 0.82 & 0.86 & 0.77 & 0.69 & 0.77 & 0.72 & 0.66 & 0.74 & 0.76 & 0.77 \\
Gansu & 0.52 & 0.54 & 0.61 & 0.45 & 0.26 & 0.26 & 0.21 & 0.24 & 0.19 & 0.22 & 0.35 \\
Guangdong & 1 & 1 & 1 & 0.99 & 1 & 1 & 0.98 & 1 & 0.95 & 0.98 & 0.99 \\
Guangxi & 0.46 & 0.45 & 0.41 & 0.46 & 0.34 & 0.35 & 0.37 & 0.39 & 0.37 & 0.39 & 0.4 \\
Guizhou & 0.4 & 0.24 & 0.25 & 0.3 & 0.17 & 0.2 & 0.15 & 0.32 & 0.27 & 0.37 & 0.27 \\
Hainan & 1 & 1 & 1 & 1 & 1 & 1 & 1 & 1 & 1 & 1 & 1 \\
Hebei & 0.58 & 0.5 & 0.48 & 0.58 & 0.5 & 0.52 & 0.56 & 0.52 & 0.52 & 0.54 & 0.53 \\
Heilongjiang & 0.21 & 0.18 & 0.16 & 0.18 & 0.13 & 0.13 & 0.4 & 0.12 & 0.09 & 0.12 & 0.17 \\
Henan & 0.62 & 0.7 & 0.59 & 0.61 & 0.47 & 0.5 & 0.44 & 0.43 & 0.38 & 0.42 & 0.52 \\
Hubei & 0.43 & 0.39 & 0.43 & 0.4 & 0.38 & 0.44 & 0.39 & 0.51 & 0.47 & 0.57 & 0.44 \\
Hunan & 0.28 & 0.28 & 0.3 & 0.25 & 0.3 & 0.35 & 0.3 & 0.34 & 0.31 & 0.68 & 0.34 \\
Inner Mongolia & 0.3 & 0.27 & 0.35 & 0.42 & 0.38 & 0.39 & 0.39 & 0.52 & 0.44 & 0.36 & 0.38 \\
Jiangsu & 1 & 1 & 0.99 & 0.99 & 0.98 & 0.97 & 0.97 & 0.99 & 1 & 1 & 0.99 \\
Jiangxi & 0.47 & 0.48 & 0.62 & 0.52 & 0.49 & 0.52 & 0.57 & 0.48 & 0.46 & 0.51 & 0.51 \\
Jilin & 0.33 & 0.37 & 0.41 & 0.54 & 0.52 & 0.53 & 0.51 & 0.55 & 0.36 & 0.53 & 0.47
\end{tabular}




\begin{tabular}{lccccccccccc} 
Liaoning & 0.58 & 0.55 & 0.56 & 0.59 & 0.55 & 0.55 & 0.55 & 0.6 & 0.53 & 0.39 & 0.55 \\
Ningxia & 0.62 & 0.46 & 0.55 & 0.52 & 0.42 & 0.38 & 0.31 & 0.37 & 0.32 & 0.43 & 0.44 \\
Qinghai & 0.76 & 0.78 & 0.73 & 0.85 & 0.76 & 0.75 & 0.58 & 0.6 & 0.59 & 0.59 & 0.7 \\
Shaanxi & 0.44 & 0.25 & 0.29 & 0.27 & 0.21 & 0.75 & 0.2 & 0.27 & 0.28 & 0.36 & 0.33 \\
Shanghai & 1 & 1 & 1 & 1 & 1 & 1 & 0.9 & 1 & 1 & 1 & 0.99 \\
Shanxi & 0.18 & 0.16 & 0.15 & 0.15 & 0.14 & 0.12 & 0.11 & 0.11 & 0.08 & 0.1 & 0.13 \\
Sichuan & 0.51 & 0.57 & 0.51 & 0.39 & 0.31 & 0.35 & 0.27 & 0.27 & 0.22 & 0.32 & 0.37 \\
Tianjin & 0.92 & 0.88 & 0.84 & 0.78 & 0.79 & 0.92 & 0.78 & 0.86 & 0.82 & 0.89 & 0.85 \\
Xinjiang & 0.24 & 0.18 & 0.18 & 0.43 & 0.19 & 0.12 & 0.12 & 0.17 & 0.09 & 0.23 & 0.2 \\
Yunnan & 0.23 & 0.24 & 0.24 & 0.2 & 0.18 & 0.18 & 0.19 & 0.22 & 0.19 & 0.24 & 0.21 \\
Zhejiang & 1 & 1 & 1 & 1 & 0.99 & 1 & 0.95 & 0.94 & 0.97 & 0.92 & 0.98 \\
\hline
\end{tabular}

According to Fig. 3a, Beijing, Guangdong, Shanghai, Hainan, Qinghai, Guangxi, Shandong, Zhejiang, Jiangsu, and Liaoning are recorded to have the highest TFEEI (0.82-1.00), whereas Guizhou, Henan, Inner Mongolia, Heilongjiang, Yunnan, and Shanxi have the lowest TFEEI (0.07-0.20). According to Fig. 3b, a TFEEI score within the range of 0.74 to 1 is evident in Jiangsu, Shandong, Guangdong, Hainan, Zhejiang, Shanghai, and Fujian. In contrast, with the score 0.07-0.26, Shanxi, Chongqing, Yunnan, Xinjiang, Heilongjiang, Sichuan, Hebei, Hubei, Hunan, Guangxi, and Guizhou show lower values. Evident in Fig. 3c, the highest TFEEI is recorded in Shanghai, Jiangsu, Shandong, Guangdong, and Hainan for the non-metallic sector, whereas the lowest TFEEI is recorded in Shanxi and Yunnan. Fig. 3d shows the highest value of TFEEI for the ferrous metal sector in Tianjin, Hebei, Shanghai, Jiangsu, and Hainan and the lowest for Heilongjiang. Furthermore, Fig. 3e shows a low value of TFEEI for the non-ferrous metal sector in Jilin, Guizhou, Xinjiang, Shanxi, Guangxi, and Heilongjiang provinces. Beijing, Shanghai, Jiangsu, Guangdong, and Hainan are considered the most energy-efficient provinces. With a special focus on the western and north-eastern regions, China's high energy-intensive industries need further improvement. With better energy and pollution control effect, Jiangxi and Sichuan show a relatively high TFEEI for metal industries. The worst value of TFEEI is recorded in the petroleum and electricity industries of the central region of Shanxi, the western 
region of Xinjiang, Yunnan, and Gansu. A significantly poor economic foundation, backward technological conditions, and low efficiency are evident in the above-mentioned provinces.

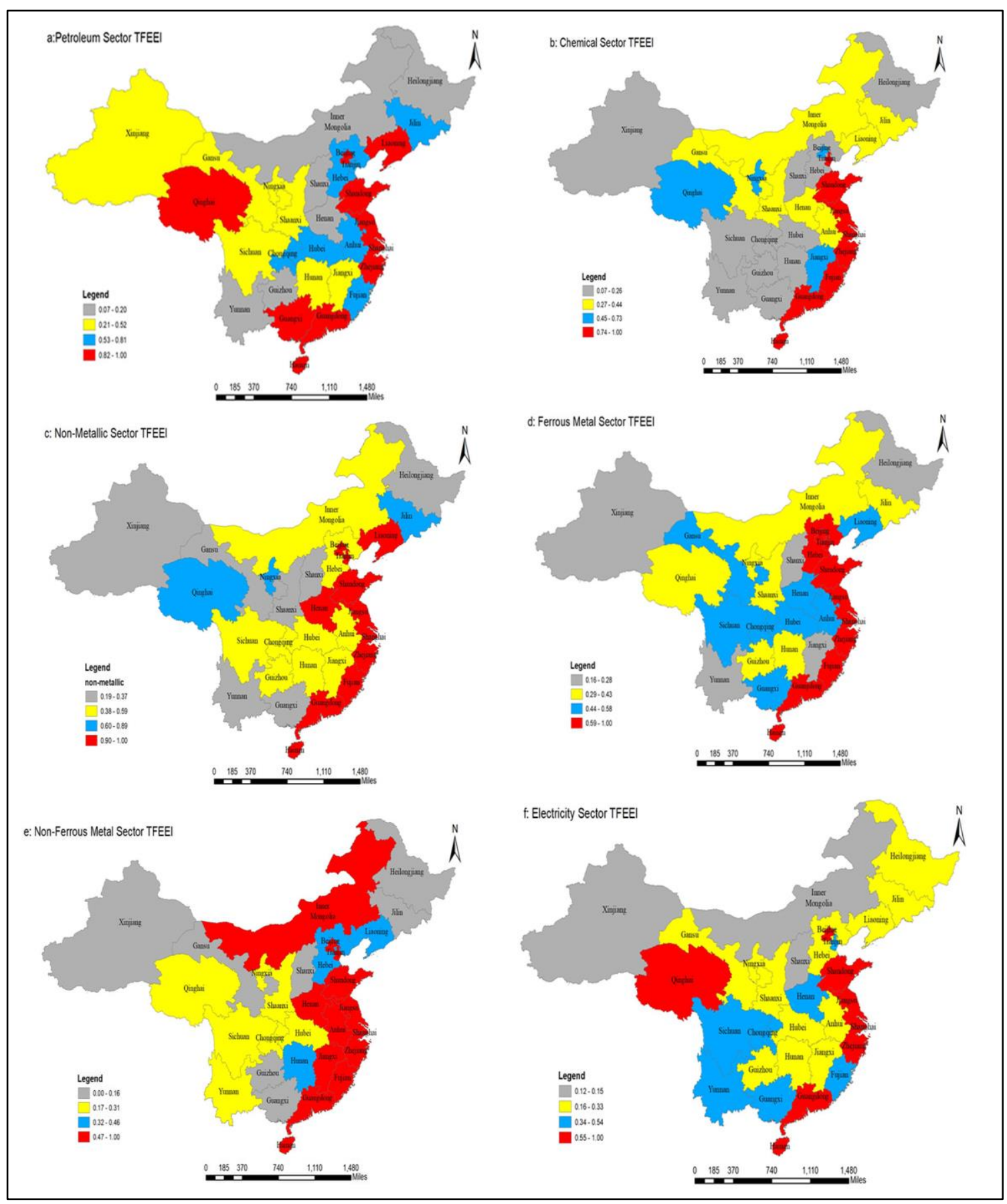

Figure 3 The spatial and temporal distribution of average TFEEI of China's six high energyintensive industries at the provincial level

\subsection{The Empirical Results of the Benchmark Model}

The system GMM approach is applied to fix the issues relevant to dynamic panel estimation stated in equation 5. System GMM takes into consideration that there is no autocorrelation 
within the disturbance terms. This approach also solves the endogeneity issue by taking lag variables. The result of the GMM test is presented in table 5. Apart from performing the GMM, the study also conducted Arellano-bond (AR) test, Sargan-Hansen and Wald chi-square tests to attain a more robust estimation result. The Arellano-Bond (AR) test comprises both first and second-order autocorrelation of residuals tests which are known as AR (1) and AR (2) respectively. The residuals of the equation are regarded as not autocorrelated if AR (2) is accepted and AR (1) is rejected. Meanwhile, to check the exogeneity among the variables, the Sargan-Hansen test is applied. Moreover, the Wald test is performed to check the level of significance of each regression.

Table 5. The result of the Dynamic panel regression

\begin{tabular}{|c|c|c|c|c|}
\hline & \multicolumn{2}{|c|}{ CCER } & \multicolumn{2}{|c|}{ MER } \\
\hline & (1) & (2) & (3) & (4) \\
\hline \multirow[t]{2}{*}{ TFEE_lag1 } & $0.3615 * * *$ & $0.3827 * * *$ & $0.3901 * * *$ & $0.4155 * * *$ \\
\hline & $(0.0014)$ & $(0.0017)$ & $(0.0023)$ & $0.0029)$ \\
\hline \multirow[t]{2}{*}{ CCER } & 0.0286 & & & \\
\hline & $(0.1551)$ & & & \\
\hline \multirow[t]{2}{*}{ CCER_lag1 } & & 0.0342 & & \\
\hline & & $(0.1137)$ & & \\
\hline \multirow[t]{2}{*}{ MER } & & & $0.0304 * *$ & \\
\hline & & & $(0.0052)$ & \\
\hline \multirow[t]{2}{*}{ MER_lag1 } & & & & $0.0795 * * *$ \\
\hline & & & & $(0.0881)$ \\
\hline \multirow[t]{2}{*}{$\mathrm{R} \& \mathrm{D}$} & $0.0342 * * *$ & $0.0350 * * *$ & $0.0294 * * *$ & $0.0301 * * *$ \\
\hline & $(0.0011)$ & $(0.0012)$ & $(0.0203)$ & $(0.0214)$ \\
\hline \multirow[t]{2}{*}{ FDI } & 0.0151 & $0.0160 *$ & -0.0209 & $0.0241 *$ \\
\hline & $(0.0014)$ & $(0.0017)$ & $(0.0159)$ & $(0.0022)$ \\
\hline \multirow[t]{2}{*}{ URBAN } & $-0.3251 *$ & -0.3607 & -0.4251 & -0.4399 \\
\hline & $(0.0445)$ & $(0.0450)$ & $(0.0624)$ & $(0.0661)$ \\
\hline
\end{tabular}




\begin{tabular}{lcccc}
\hline EXP & $-0.0009^{* *}$ & $-0.0011^{* * *}$ & $-0.0010^{* * *}$ & $-0.0012^{* * *}$ \\
& $(0.0006)$ & $(0.0008)$ & $(0.0009)$ & $(0.0010)$ \\
IND & $0.0120^{* * *}$ & $0.0135^{* * *}$ & $0.0201 * * *$ & $0.0263 * * *$ \\
GDP & $(0.0038)$ & $(0.0040)$ & $(0.0114)$ & $(0.0118)$ \\
& $-0.0293 * * *$ & $-0.0311^{* * *}$ & $-0.0413 * * *$ & $-0.0438^{* * *}$ \\
Constant & $(0.0046)$ & $(0.0053)$ & $(0.0058)$ & $(0.0059)$ \\
& $1.0384 * * *$ & $1.0586 * * *$ & $1.1112^{* * *}$ & $1.1477 * * *$ \\
AR (1) test & $(0.1170)$ & $(0.1225)$ & $(0.0519)$ & $(0.0701)$ \\
& -2.0632 & -2.0841 & -2.4149 & -2.5243 \\
AR (2) test & {$[0.023]$} & {$[0.023]$} & {$[0.019]$} & {$[0.013]$} \\
& -1.1591 & -1.2374 & -1.2580 & -1.3001 \\
Sargan test & {$[0.171]$} & {$[0.138]$} & {$[0.166]$} & {$[0.154]$} \\
& 21.3797 & 19.9903 & 23.5612 & 18.5531 \\
& {$[0.068]$} & {$[0.069]$} & {$[0.11]$} & {$[0.139]$} \\
& 176396 & 280449 & 192133 & 305156 \\
\hline
\end{tabular}

Note: Standard errors are in parentheses (). ${ }^{* * *}=1 \%$ significant level; $* *=5 \%$ significant level and $*=10 \%$ significant level

Table 5 shows the result of dynamic regression analysis for the variables under study with four different models. It is observed that lagged TFEEI coefficients are positive and statistically significant at $1 \%$ significance level showing that the present TFEEI performance is affected by the performance of previous period's TFEEI. It is further observed that the coefficient of both CER and MER is 0.0286 and 0.0304 respectively but only MER is statistically significant at 5\% level. This reveals that market-based environment regulation might have a positive influence on the improvement of TFEEI and command-and-control environmental regulation have no significant contribution for TFEEI growth. This goes in line with the Porter effect for the case of China. 
Meanwhile, the regression estimation of the control variables shows that both research and development and industry structure positively affect the TEFFI at $1 \%$ significant level in all cases. This affirms that spending more on research and development and making industry structure optimum might accelerate the growth of TEFFI. On the other hand, both GDP and export negatively impact the TEFFI. Besides, it is observed that both FDI and urbanization have no significant influence on TEFFI improvement.

Considering the probable lag effect of environmental regulation, the estimation of Both Model 2 and model 4 are performed taking the lagged value of MER and CER. The results show the same scenario as the baseline regression as it is seen that there is existence of statistically significant of MER over TFEEI and the control variables also consistency with the estimated coefficients. However, for the case of CCER, the coefficients (0.0795) of lagged variables are found to be positive and statistically significant at 5\% level proving that TFEEI growth is affected by the lags. It refers to the fact that in case of a rigorous CCER practice the influence of "innovation offset" based on is more powerful that influence of "compliance cost" effect in the long run. This proposition matches with the findings of Guo and Yuan, (2020), who argues that taking the lagged variables instead of current variables might increase to chances to generate a positive and significant effect on energy efficiency.

\subsection{The empirical results of the moderating effect of $R \& D$}

Though all the moderating coefficients are seen positive, only MER and R\&D are statistically significant with a 5\% level (table 6). This proposes that the moderating effect existent for environmental regulation. The result of the regression estimation shows that more R\&D spending can boost TFEEI growth and contemplate the innovation offset effect steamed from market-based environmental regulation. $R \& D$ spending has both direct and indirect impact on the TFEEI of manufacturing sector. China controls the industrial pollution emission through command-and-control environment regulation by setting stringent emission limits and 
advanced technological standards. However, unlike MER, the command-and-control environmental regulation has little flexibleness, and this makes the improvement of energy efficiency through accelerating the effect of "innovation offset" for the short run.

Porter argues that, by making well-structured environmental regulation based on the innovation effect, a positive effect can be established on R\&D and technology empowerment. Therefore, the impact of moderation effect of R\&D and environmental regulation on TFEEI needs to be studied further to enhance TFEEI to the highest level possible in view of that, the moderating factors of R\& D and CER are includes in the dynamic panel modelling of this study

Table 6. Regression results of research \& development effect on TFEEI.

\begin{tabular}{|c|c|c|c|c|}
\hline & \multicolumn{2}{|c|}{ CER } & \multicolumn{2}{|c|}{ MER } \\
\hline & (5) & (6) & (7) & (8) \\
\hline \multirow[t]{2}{*}{ TFEE_lag1 } & $0.3711 * * *$ & $0.4028 * * *$ & $0.3996 * * *$ & $0.4154 * * *$ \\
\hline & $(0.0026)$ & $(0.0031)$ & $(0.0011)$ & $(0.0013)$ \\
\hline \multirow[t]{2}{*}{ CCER } & 0.0293 & & & \\
\hline & $(0.0556)$ & & & \\
\hline \multirow[t]{2}{*}{ CCER_lag1 } & & 0.0415 & & \\
\hline & & $(0.0603)$ & & \\
\hline \multirow[t]{2}{*}{ MER } & & & $0.0322 * *$ & \\
\hline & & & $(0.0046)$ & \\
\hline \multirow[t]{2}{*}{ MER_lag1 } & & & & $0.0519 * * *$ \\
\hline & & & & $(0.0054)$ \\
\hline \multirow[t]{2}{*}{ CCER*R\&D } & 0.0410 & & & \\
\hline & $(0.0069)$ & & & \\
\hline \multirow[t]{2}{*}{ CCER_lag1*R\&D } & & 0.0466 & & \\
\hline & & $(0.0072)$ & & \\
\hline \multirow[t]{2}{*}{ MER*R\&D } & & & $0.0912 * *$ & \\
\hline & & & $(0.1120)$ & \\
\hline \multirow[t]{2}{*}{ MER_lag1*R\&D } & & & & $0.1032 * *$ \\
\hline & & & & $(0.0589)$ \\
\hline \multirow[t]{2}{*}{$\mathrm{R} \& \mathrm{D}$} & $0.0306 * * *$ & $0.0323 * * *$ & $0.0375 * * *$ & $0.0391 * * *$ \\
\hline & $(0.0033)$ & $(0.0042)$ & $(0.0046)$ & $(0.0051)$ \\
\hline
\end{tabular}




\begin{tabular}{|c|c|c|c|c|}
\hline \multirow[t]{2}{*}{ FDI } & 0.0158 & $0.0183^{*}$ & 0.0162 & 0.0204 \\
\hline & $(0.0020)$ & $(0.0021)$ & $(0.0017)$ & $(0.0018)$ \\
\hline \multirow[t]{2}{*}{ URBAN } & $-0.2491^{*}$ & -0.3157 & -0.3466 & 0.0112 \\
\hline & $(0.0248)$ & $(0.0346)$ & $(0.0516)$ & $(0.1737)$ \\
\hline \multirow[t]{2}{*}{ EXP } & $-0.0006^{* *}$ & $-0.0009 * * *$ & $-0.0010^{* *}$ & -0.0013 \\
\hline & $(0.0002)$ & $(0.0003)$ & $(0.0001)$ & $(0.0002)$ \\
\hline \multirow[t]{2}{*}{ IND } & $0.0122 * *$ & $0.0126^{* * *}$ & $0.0239 * * *$ & $0.0301 * *$ \\
\hline & $(0.0046)$ & $(0.0051)$ & $(0.0054)$ & $(0.0056)$ \\
\hline \multirow[t]{2}{*}{ GDP } & $-0.0193 * * *$ & $-0.0234 * * *$ & $-0.0201 * * *$ & $-0.0355^{* * *}$ \\
\hline & $(0.0177)$ & $(0.0186)$ & $(0.0170)$ & (0.0199) \\
\hline \multirow[t]{2}{*}{ Constant } & $1.1383 * * *$ & $1.2353 * * *$ & $1.1099 * * *$ & $1.0723 * * *$ \\
\hline & $(0.0390)$ & $(0.0490)$ & $(0.0590)$ & $(0.0590)$ \\
\hline \multirow[t]{2}{*}{ AR(1) test } & -2.2932 & -2.3024 & -2.1575 & -2.1235 \\
\hline & {$[0.023]$} & {$[0.023]$} & [0.019] & {$[0.013]$} \\
\hline \multirow[t]{2}{*}{$\mathrm{AR}(2)$ test } & -1.3401 & -1.2552 & -1.2380 & -1.1895 \\
\hline & {$[0.1749]$} & {$[0.1411]$} & {$[0.1382]$} & {$[0.1312]$} \\
\hline \multirow[t]{2}{*}{ Sargan test } & 21.3771 & 20.1098 & 17.8685 & 15.596 \\
\hline & {$[0.0752]$} & [0.0706] & [0.1123] & [0.1269] \\
\hline \multirow[t]{2}{*}{ Wald test } & 198472.3 & 300239.2 & 232216 & 291644.1 \\
\hline & {$[0]$} & {$[0]$} & {$[0]$} & {$[0]$} \\
\hline
\end{tabular}

Note: Standard errors are in parentheses ()$. * *=1 \%$ significant level; $* *=5 \%$ significant level and $*=10 \%$ significant level

\subsection{The results of the threshold model}

The threshold effect model is tested following three different procedures. First, the value and quantity of the threshold is determined with sample endogeneity. Then, in accordance with progressive distribution theory, the confidence interval of the threshold parameter is formed. Finally, by using self-sampling technique, the significance level of the threshold is evaluated. To ascertain the number of thresholds, three successive investigations are conducted by taking the assumptions of single, double and multiple thresholds. After the investigation of the number of environmental regulation thresholds, the value of F-statistic and its corresponding P-value 
are obtained (Table 7). It is evident from Table 8 that both single and double thresholds test results are positive and significant at 5\% level while triple threshold fail to reach the required level of significance.

Table 7. Results of the threshold effect

\begin{tabular}{|c|c|c|c|c|}
\hline Model & F-statistic & $\mathrm{P}$-value & F-statistic & $\mathrm{P}$-value \\
\hline & \multicolumn{2}{|c|}{ CCER } & \multicolumn{2}{|c|}{ MER } \\
\hline Single threshold & 34.69 & 0.142 & $49.88 * *$ & 0.042 \\
\hline Double threshold & $16.01 * * *$ & 0.0037 & 12.36 & 0.175 \\
\hline Triple threshold & 6.93 & 0.827 & 4.322 & 0.697 \\
\hline
\end{tabular}

Although the single and triple threshold cannot reach the required level of significance, CCER in double thresholds test result is positive and significant at $1 \%$ in Tab. 8. With the significance of only 5\%, a single-threshold model exists for market-based environmental regulations. -3.3351 and -3.3403 show the values for the double threshold of the environmental regulation; according to test results of the threshold effect, the confidence interval shown here is $95 \%$.

Table 8. The estimation result of threshold value and its confidence interval

\begin{tabular}{|c|c|c|c|c|}
\hline & Estimate & $\mathrm{Cl}: 95 \%$ & Estimate & $\mathrm{Cl}: 95 \%$ \\
\hline & & CER & MER & \\
\hline Threshold value $\gamma_{1}$ & -3.3403 & {$[-3.4124,-3.4081]$} & 4.169 & {$[4.059,4.204]$} \\
\hline Threshold value $\gamma_{2}$ & -3.3351 & {$[-3.3386,-3.3338]$} & & \\
\hline
\end{tabular}

Table 9 presents the results of regression for the threshold model. As, the values of command-and-control environmental regulation (CCER) and market based environmental regulations exceed the levels of corresponding thresholds, the positive impact of environmental regulation on TFEI gradually increases. It is observed that the coefficient estimates for threshold effect model are $0.0571,0.012$, respectively and there is an upbound of their corresponding level of significance from $10 \%$ to $1 \%$. This proposes that when the pull-out position of the environmental regulations improves by $1 \%$, the total factor energy efficiency of the high emitting industries increases by $1.2 \%$ to $5.7 \%$. It proves that the "J-shape" has a 
marginal Growth trend. This investigation results depicts the way different levels of regulations affect the causality between the surrounded position of environmental regulations, the TFEEI, and the threshold or turning point in this relationship.

Table 9. Regression results of the threshold effect model.

\begin{tabular}{|c|c|c|}
\hline Variable & CCER & MER \\
\hline & (9) & (10) \\
\hline & SYS-GMM & SYS-GMM \\
\hline \multirow[t]{2}{*}{ GTFEEit-1 } & $0.8618 * * *$ & $0.8846 * * *$ \\
\hline & -44.46 & -42.4 \\
\hline \multirow[t]{2}{*}{$C C E R \leq-3.3403$} & 0.571 & \\
\hline & $(0.004)$ & \\
\hline \multirow[t]{2}{*}{$-3.3403<\mathrm{CC} E R \leq-3.3351$} & $1.200 * * *$ & \\
\hline & $(0.011)$ & \\
\hline \multirow[t]{2}{*}{$C C E R>-3.3351$} & $2.263 * *$ & \\
\hline & $(0.007)$ & \\
\hline \multirow[t]{2}{*}{$M E R \leq 4.196$} & & $0.162 * * *$ \\
\hline & & $(0.025)$ \\
\hline \multirow[t]{2}{*}{$M E R>4.196$} & & 0.089 \\
\hline & & $(0.161)$ \\
\hline \multirow[t]{2}{*}{$F D I$} & 0.035 & 0.018 \\
\hline & $(0.016)$ & $(0.022)$ \\
\hline \multirow[t]{2}{*}{$R \& D$} & $0.051 * * *$ & $0.093 * * *$ \\
\hline & $(0.000)$ & $(0.001)$ \\
\hline \multirow[t]{2}{*}{$U R B A N$} & -0.630 & -0.556 \\
\hline & $(0.017)$ & $(0.129)$ \\
\hline \multirow[t]{2}{*}{$E C S$} & $-0.008 * * *$ & $-0.014 * *$ \\
\hline & $(0.002)$ & $(0.010)$ \\
\hline \multirow[t]{2}{*}{$I N D$} & 0.012 & 0.033 \\
\hline & $(0.169)$ & $(0.208)$ \\
\hline \multirow[t]{2}{*}{$G D P P$} & $-0.086^{* * *}$ & $-0.091 * *$ \\
\hline & $(0.054)$ & $(0.060)$ \\
\hline \multirow[t]{2}{*}{ Constant } & $0.766 * * *$ & $1.052 * * *$ \\
\hline & $(0.264)$ & $(0.521)$ \\
\hline \multirow[t]{2}{*}{$\operatorname{AR}(2)$} & 1.1 & 1.11 \\
\hline & {$[0.271]$} & {$[0.268]$} \\
\hline
\end{tabular}




\begin{tabular}{lcc}
\hline Hansen test & 27.95 & 27.16 \\
& {$[0.859]$} & {$[0.939]$} \\
Wald test & $192,945.17 * * *$ & $130,556.07 * * *$ \\
& {$[0.000]$} & {$[0.000]$} \\
$\mathrm{N}$ & 330 & 330 \\
\hline
\end{tabular}

Note: Standard errors are in parentheses (). ${ }^{* * *}=1 \%$ significant level; $* *=5 \%$ significant level and $*=10 \%$ significant level

\subsection{Robustness Tests}

To avoid the outliers adversely influencing the forecasted results, a 5\% tail ended test is applied for the entire dataset. In Column 11 of the Table 10, it is observed that there is no significant deviation among the regression results of the benchmark model, the coefficient and significance level. The robustness test results reveal that the earlier estimations are more reliable. The residual sum of squares is shown as the minimum objective function for the system GMM regression equation. This proposes that regression result can be influenced by the extreme values quite easily which eventually might make the result a biased one. To overcome this limitation, the model of quantile regression is employed to check the robustness of the proposed model (Bosch et al., 1995). This model is applied to describe the changes take place in the conditional quantile of the dependent variable with the changes in the independent variable. It is observed from the columns 12-16 of Table 11 that the regression coefficients of the TFEEI position in the five typical quantiles (10th, 30th, 50th, 70th and 90th) are have positive and statistically significant trends and it proves that the estimation is robust and reliable

Table 10. The regression results of robustness test.

\begin{tabular}{lcccccc}
\hline Variables & $(11)$ & $(12)$ & $(13)$ & $(14)$ & $(15)$ & $(16)$ \\
\hline TFEE_lag1 & \multicolumn{1}{c}{$\begin{array}{c}\text { 10th } \\
\text { quantile }\end{array}$} & $\begin{array}{c}30 \text { th } \\
\text { quantile }\end{array}$ & $\begin{array}{c}50 \text { th } \\
\text { quantile }\end{array}$ & $\begin{array}{c}70 \text { th } \\
\text { quantile }\end{array}$ & $\begin{array}{c}\text { 90th } \\
\text { quantile }\end{array}$ \\
& $1.771^{* * *}$ & 0.036 & $0.975^{* * *}$ & $0.568^{* *}$ & $0.978^{* *}$ & $1.763^{* * *}$ \\
CCER & -0.4704 & -0.469 & -0.336 & -0.279 & -0.402 & -0.588 \\
\hline
\end{tabular}




\begin{tabular}{|c|c|c|c|c|c|c|}
\hline & $(0.2846)$ & & & & & \\
\hline MER & $\begin{array}{c}1.494 * * * \\
(0.2846)\end{array}$ & & & & & \\
\hline \multirow[t]{2}{*}{ RD } & $0.149 * * *$ & 0.030 & $0.070^{*}$ & $0.104 * * *$ & $0.156 * *$ & $0.213 * * *$ \\
\hline & $(0.0475)$ & $(0.0630)$ & $(0.0392)$ & $(0.0387)$ & $(0.0622)$ & $(0.0669)$ \\
\hline \multirow[t]{2}{*}{ FDI } & $-0.539 * *$ & -0.008 & $-0.167 * *$ & $-0.180 * * *$ & $-0.243 * * *$ & $-0.173 *$ \\
\hline & $(0.0652)$ & -0.128 & -0.082 & -0.0636 & -0.082 & -0.0903 \\
\hline \multirow[t]{2}{*}{$U R B A N$} & 0.630 & -0.556 & -0.557 & -0.482 & -0.408 & -0.409 \\
\hline & $(0.017)$ & -0.129 & 0.871 & -0.241 & -0.353 & 0.647 \\
\hline \multirow[t]{2}{*}{$E X P$} & $-0.008 * * *$ & $-0.014 * *$ & $-0.014 * *$ & $-0.008 * * *$ & $-0.014 * *$ & $-0.014 * *$ \\
\hline & $(0.002)$ & -0.01 & -0.01 & -0.018 & -0.026 & -0.026 \\
\hline \multirow[t]{2}{*}{$I N D$} & $0.012 * * *$ & $0.033 * * *$ & $0.033 * * *$ & $0.054 * * *$ & $0.075 * * *$ & $0.075 * * *$ \\
\hline & $(0.169)$ & -0.208 & -0.208 & -0.247 & -0.286 & -0.286 \\
\hline \multirow[t]{2}{*}{$G D P$} & $-0.086^{* * *}$ & $-0.091 * *$ & $-0.091 * *$ & $-0.086 * * *$ & $-0.091 * *$ & $-0.091 * *$ \\
\hline & $(0.054)$ & -0.06 & 0.94 & -0.066 & -0.072 & 0.928 \\
\hline \multirow[t]{2}{*}{ Constant } & $3.285 * * *$ & $0.169 * * *$ & $0.126 * * *$ & $0.465 * *$ & $0.701 * *$ & $1.218 * * *$ \\
\hline & $(0.9409)$ & $(0.3260)$ & $(0.1410)$ & $(0.1860)$ & $(0.2850)$ & $(0.2890)$ \\
\hline Observations & 140 & 140 & 140 & 140 & 140 & 140 \\
\hline R-squared & 0.6323 & & & & & \\
\hline $\mathrm{F}$ & 52.45 & & & & & \\
\hline
\end{tabular}

Note: Standard errors are in parentheses ()$. * * *=1 \%$ significant level; $* *=5 \%$ significant level and $*=10 \%$ significant level

\section{Conclusion and Policy Implication}

This work uses 2008-17 panel data from China's 30 provinces to assess the country's energyintensive industries' environmental regulations in the context of China's expanding economy and global warming concerns. The Total Factor Energy Efficiency Index (TFEEI) is computed through the Non-radial Direction Distance Function (NDDF), which is then used to compare two environmental regulations through dynamic panel models. Although results show a significant increase in the TFEEI of the selected industries, much room improvement can be achieved, where the overall average TFEEI at 0.55 and 0.58 . Most of the eastern provinces have higher TFEEI compared to the western and north-eastern provinces. Moreover, the TFEEI 
of the western provinces is lower than that of the central and eastern provinces, owing to backward technology and a low economic base. The high energy-intensive industries in Heilongjiang and Liaoning developed earlier as they are the old industrial area of north-eastern China. Hence, the obsolete technology in these industries results in a low level of TFEEI. The non-metallic and ferrous metal sectors showed the best output during the study period, while the chemical and non-ferrous metal sectors showed a mixed pattern.

The results indicate that CCER, MER, and TFEEI have a strong inverted U-shaped association in high energy-intensive industries. The coefficient of both CER and MER (0.0286 and 0.0304) are statistically positive. However, at a 5\% level, only MER is statistically significant, suggesting that market-based environmental regulation could positively affect TFEEI enhancement, and appropriate regulations are helping to boost TFEEI. The results of the research affirm the efficacy of environmental regulations in the promotion of TFEEI in energyintensive industries in China.

Based on the findings of this study, policymakers should understand the various levels of efficacy of environmental legislation to make more informed decisions. CCERs should be obligatory, resulting in a shortage of choices for the organization's renewable creative technologies. Policymakers should aggressively apply market-based environmental regulations to expand the regional industry market platform, encourage new research on emissions taxes and carbon trading, and eventually gain greater pollution control. The government should take appropriate steps in environmental governance to boost the TFEEI of energy-intensive industries and pay attention to each sector at the regional level.

\section{Ethical Approval and Consent to Participate}


The authors declare that they have no known competing financial interests or personal relationships that seem to affect the work reported in this article. We declare that we have no human participants, human data or human tissues.

\section{Consent for Publication}

We do not have any individual person's data in any form.

\section{Author Contribution}

Thanh Quang, Ngo: Conceptualization, Data curation, Methodology, Writing - original draft, Data curation, Visualization. review \& editing, Writing - review \& editing and software, Visualization, supervision, editing.

\section{Funding}

This research is funded by University of Economics Ho Chi Minh City, Vietnam.

\section{Competing interest statement}

We declare that there is no conflict of interest.

\section{Availability of data and materials}

The data that support the findings of this study are openly available on request.

\section{Reference}

Antonietti, R., Fontini, F., 2019. Does energy price affect energy efficiency? Cross-country panel evidence. Energy Policy 129, 896-906. https://doi.org/10.1016/j.enpol.2019.02.069

Bi, G.B., Song, W., Zhou, P., Liang, L., 2014. Does environmental regulation affect energy efficiency in China's thermal power generation $\alpha$ Empirical evidence from a slacks-based DEA model. Energy Policy. https://doi.org/10.1016/j.enpol.2013.10.056

Bosch, R.J., Ye, Y., Woodworth, G.G., 1995. A convergent algorithm for quantile regression with smoothing splines. Comput. Stat. Data Anal. https://doi.org/10.1016/01679473(94)00018-E

Chen, X., Lin, B., 2020. Energy and $\mathrm{CO}_{2}$ emission performance: A regional comparison of 
China's non-ferrous metals industry. J. Clean. Prod. https://doi.org/10.1016/j.jclepro.2020.123168

Chien, F., Sadiq, M., Kamran, H.W. et al. Co-movement of energy prices and stock market return: environmental wavelet nexus of COVID-19 pandemic from the USA, Europe, and China. Environ Sci Pollut Res (2021). https://doi.org/10.1007/s11356-021-12938-2

Chung, Y.H., Färe, R., Grosskopf, S., 1997. Productivity and undesirable outputs: A directional distance function approach. J. Environ. Manage. 51, 229-240. https://doi.org/10.1006/jema.1997.0146

Du, W., Wang, F., Li, M., 2020. Effects of environmental regulation on capacity utilization: Evidence from energy enterprises in China. Ecol. Indic. https://doi.org/10.1016/j.ecolind.2020.106217

Färe, R., Grosskopf, S., 2010. Directional distance functions and slacks-based measures of efficiency. Eur. J. Oper. Res. 200, 320-322. https://doi.org/10.1016/j.ejor.2009.01.031

Geng, Z., Zeng, R., Han, Y., Zhong, Y., Fu, H., 2019. Energy efficiency evaluation and energy saving based on DEA integrated affinity propagation clustering: Case study of complex $\begin{array}{lll}\text { petrochemical } \quad \text { industries. } & \text { Energy } & \text { 863-875. }\end{array}$ https://doi.org/10.1016/j.energy.2019.05.042

Greenstone, M., Hanna, R., 2014. Environmental regulations, air and water pollution, and infant mortality in India. Am. Econ. Rev. https://doi.org/10.1257/aer.104.10.3038

Guo, R., Yuan, Y., 2020. Different types of environmental regulations and heterogeneous influence on energy efficiency in the industrial sector: Evidence from Chinese provincial data. Energy Policy. https://doi.org/10.1016/j.enpol.2020.111747

Hansen, B.E., 1999. Threshold effects in non-dynamic panels: Estimation, testing, and inference. J. Econom. https://doi.org/10.1016/S0304-4076(99)00025-1

Jefferson, G.H., Tanaka, S., Yin, W., 2013. Environmental Regulation and Industrial Performance: Evidence from Unexpected Externalities in China. SSRN Electron. J. https://doi.org/10.2139/ssrn.2216220

Khoshnevisan, B., Rafiee, S., Omid, M., Mousazadeh, H., 2013. Reduction of $\mathrm{CO}_{2}$ emission by improving energy use efficiency of greenhouse cucumber production using DEA approach. Energy 55, 676-682. https://doi.org/10.1016/J.ENERGY.2013.04.021

Li, J., Lin, B., 2017. Does energy and $\mathrm{CO}_{2}$ emissions performance of China benefit from regional integration? Energy Policy. https://doi.org/10.1016/j.enpol.2016.10.036

Li, M., Mi, Z., Coffman, D.M., Wei, Y.M., 2018. Assessing the policy impacts on non-ferrous metals industry's $\mathrm{CO}_{2}$ reduction: Evidence from China. J. Clean. Prod. https://doi.org/10.1016/j.jclepro.2018.05.015 
Lin, B., Chen, X., 2020. Environmental regulation and energy-environmental performanceEmpirical evidence from China's non-ferrous metals industry. J. Environ. Manage. https://doi.org/10.1016/j.jenvman.2020.110722

Lin, B., Chen, X., 2019. Evaluating the $\mathrm{CO}_{2}$ performance of China's non-ferrous metals Industry: A total factor meta-frontier Malmquist index perspective. J. Clean. Prod. https://doi.org/10.1016/j.jclepro.2018.10.278

Lin, B., Jia, Z., 2019. How does tax system on energy industries affect energy demand, CO2 emissions, and economy in China? Energy Econ. https://doi.org/10.1016/j.eneco.2019.104496

Liu, H., Fan, J., Zeng, Y., Guo, R., 2019a. Spatio-temporal differences in carbon intensity in high-energy-intensive industry and its influence factors in China. Shengtai Xuebao/ Acta Ecol. Sin. https://doi.org/10.5846/stxb201809121957

Liu, H., Fan, J., Zhou, K., Wang, Q., 2019b. Exploring regional differences in the impact of high energy-intensive industries on $\mathrm{CO} 2$ emissions: Evidence from a panel analysis in China. Environ. Sci. Pollut. Res. https://doi.org/10.1007/s11356-019-05865-w

Ma, D., Fei, R., Yu, Y., 2019. How government regulation impacts on energy and CO2 emissions performance in China's mining industry. Resour. Policy. https://doi.org/10.1016/j.resourpol.2018.11.013

Meng, L., Li, Y., Zhang, S., 2020. Regional differences of carbon emissions in the coal industry based on FPGA and wireless sensors. Microprocess. Microsyst. 103489. https://doi.org/10.1016/j.micpro.2020.103489

Nassiri, S.M., Singh, S., 2009. Study on energy use efficiency for paddy crop using data envelopment analysis (DEA) technique. Appl. Energy 86, 1320-1325. https://doi.org/10.1016/j.apenergy.2008.10.007

Peng, X., 2020. Strategic interaction of environmental regulation and green productivity growth in China: Green innovation or pollution refuge? Sci. Total Environ. https://doi.org/10.1016/j.scitotenv.2020.139200

Poudineh, R., Sen, A., Fattouh, B., 2020. An integrated approach to electricity sector reforms in the resource rich economies of the MENA. Energy Policy. https://doi.org/10.1016/j.enpol.2019.111236

Sadiq, M., Singh, J., Raza, M., \& Mohamad, S. (2020). The Impact of Environmental, Social and Governance Index on Firm Value: Evidence from Malaysia. International Journal of Energy Economics and Policy, 10(5), 555-562.

Shao, C., Guan, Y., Wan, Z., Chu, C., Ju, M., 2014. Performance analysis of CO2 emissions and energy efficiency of metal industries in China. J. Environ. Manage. 
https://doi.org/10.1016/j.jenvman.2013.12.025

Song, M.-L., Zhang, L.-L., Liu, W., Fisher, R., 2013. Bootstrap-DEA analysis of BRICS' energy efficiency based on small sample data. Appl. Energy 112, 1049-1055. https://doi.org/10.1016/J.APENERGY.2013.02.064

Wang, J., Hu, M., Tukker, A., Rodrigues, J.F.D., 2019. The impact of regional convergence in energy-intensive industries on China 's $\mathrm{CO}_{2}$ emissions and emission goals. Energy Econ. https://doi.org/10.1016/j.eneco.2019.01.024

Wang, Z., He, W., Wang, B., 2017. Performance and reduction potential of energy and CO2 emissions among the APEC's members with considering the return to scale. Energy. https://doi.org/10.1016/j.energy.2017.07.059

Wu, H., Hao, Y., Ren, S., 2020. How do environmental regulation and environmental decentralization affect green total factor energy efficiency: Evidence from China. Energy Econ. 91. https://doi.org/10.1016/j.eneco.2020.104880

Xin-gang, Z., Shu-ran, H., 2020. Does market-based electricity price affect China's energy efficiency? Energy Econ. https://doi.org/10.1016/j.eneco.2020.104909

Zhang, L., Wang, Q., Zhang, M., 2021. Environmental regulation and CO2 emissions: Based on strategic interaction of environmental governance. Ecol. Complex. https://doi.org/10.1016/j.ecocom.2020.100893

Zhang, N., Choi, Y., 2014. A note on the evolution of directional distance function and its development in energy and environmental studies 1997-2013. Renew. Sustain. Energy Rev. https://doi.org/10.1016/j.rser.2014.01.064

Zhang, W.W., Zhao, B., Gu, Y., Sharp, B., Xu, S.C., Liou, K.N., 2020. Environmental impact of national and subnational carbon policies in China based on a multi-regional dynamic CGE model. J. Environ. Manage. 270. https://doi.org/10.1016/j.jenvman.2020.110901

Zhang, Y., Song, Y., 2021. Environmental regulations, energy and environment efficiency of China's metal industries: A provincial panel data analysis. J. Clean. Prod. https://doi.org/10.1016/j.jclepro.2020.124437

Zhang, Y., Xiong, Y., Li, F., Cheng, J., Yue, X., 2020. Environmental regulation, capital output and energy efficiency in China: An empirical research based on integrated energy prices. Energy Policy. https://doi.org/10.1016/j.enpol.2020.111826

Zhou, P., Ang, B.W., Poh, K.L., 2006. Comparing aggregating methods for constructing the composite environmental index: An objective measure. Ecol. Econ. 59, 305-311. https://doi.org/10.1016/J.ECOLECON.2005.10.018

Zhou, P., Ang, B.W., Wang, H., 2012. Energy and CO2emission performance in electricity generation: A non-radial directional distance function approach. Eur. J. Oper. Res. 221, 
625-635. https://doi.org/10.1016/j.ejor.2012.04.022

Zhou, P., Poh, K.L., Ang, B.W., 2007. A non-radial DEA approach to measuring environmental performance. Eur. J. Oper. Res. 178, 1-9. https://doi.org/10.1016/j.ejor.2006.04.038 
Figures
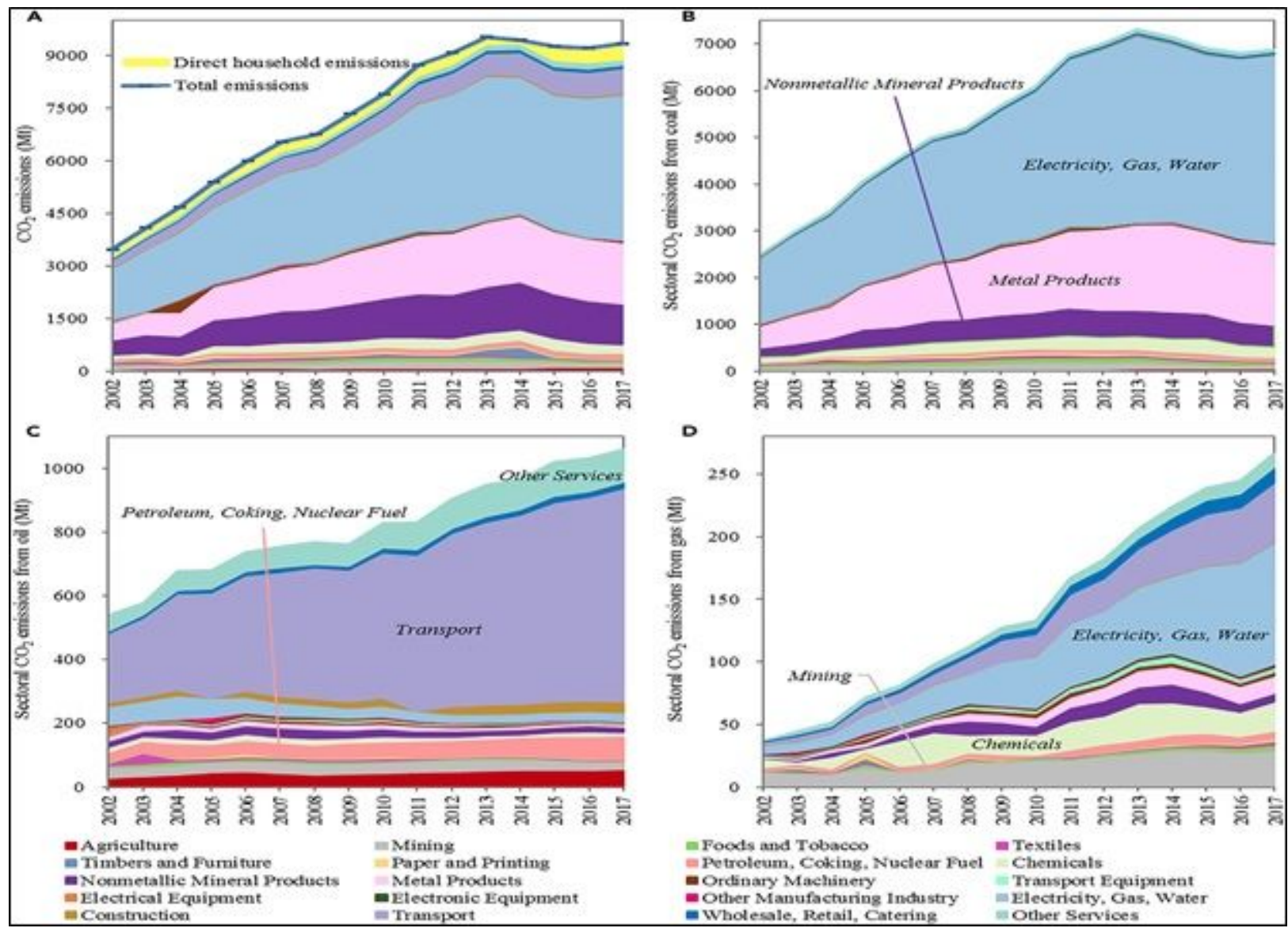

Timbers and Purniture

Nonmetallie Mineral Proxtuets

= Mining

Paper and Printing

E Nonmetallie Mineral

Metal Produets

Construction

Electronic Equipment

Eransport

Other Services

\section{Figure 1}

Carbon emission scenario of Chinese industries (2002-2017) 


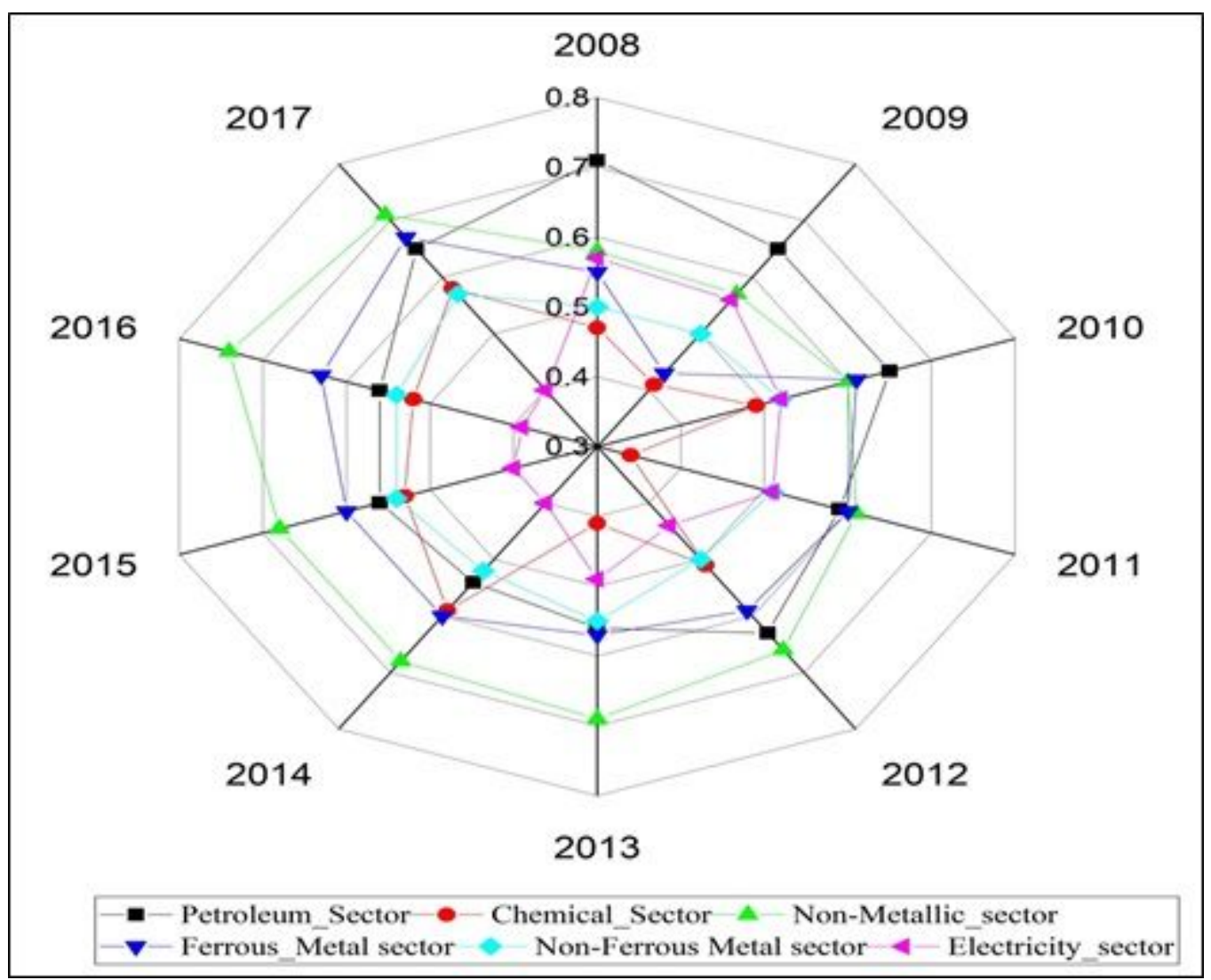

Figure 2

The TFEEl of China's six high energy-intensive industries from 2008 to 2017 


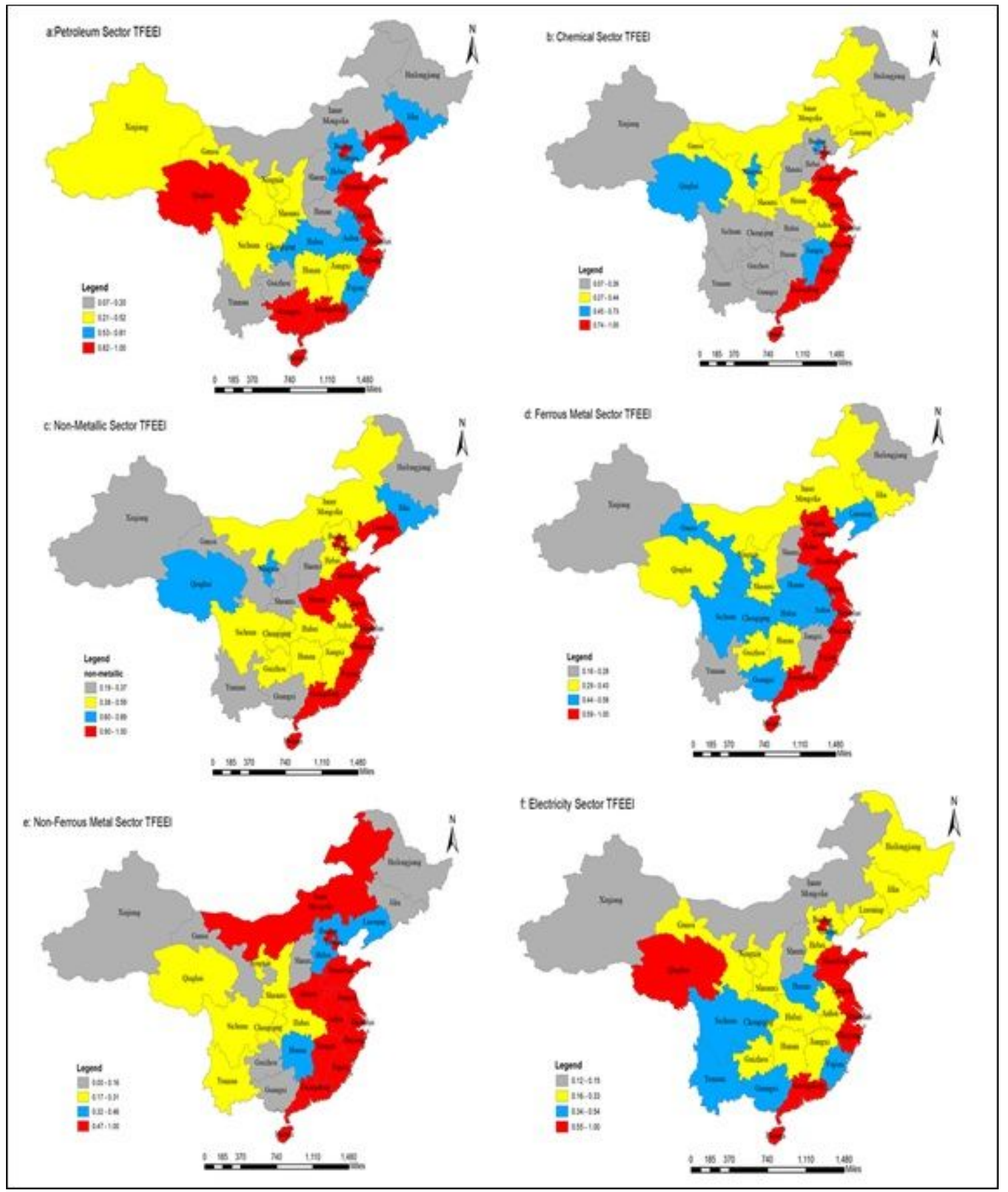

Figure 3

The spatial and temporal distribution of average TFEEI of China's six high energy-intensive industries at the provincial level. Note: The designations employed and the presentation of the material on this map do not imply the expression of any opinion whatsoever on the part of Research Square concerning the legal status of any country, territory, city or area or of its authorities, or concerning the delimitation of its frontiers or boundaries. This map has been provided by the authors. 